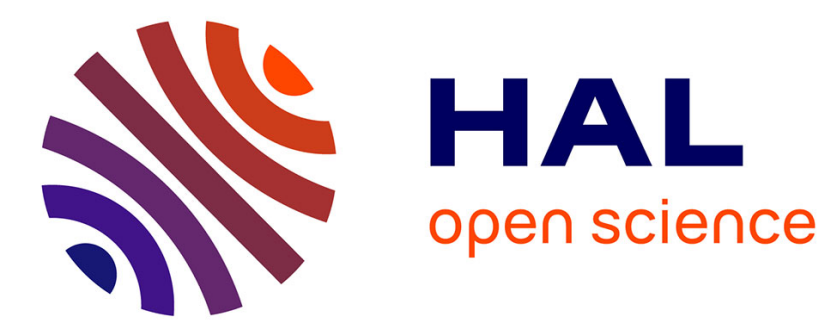

\title{
Recent climate variability around the Kerguelen Islands (Southern Ocean) seen through weather regimes
}

\author{
Benjamin Pohl, Thomas Saucède, Julien Pergaud, Jean-Pierre Féral, Yves \\ Richard, Vincent Favier, Deborah Verfaillie, Ylber Krasniqi
}

\section{- To cite this version:}

Benjamin Pohl, Thomas Saucède, Julien Pergaud, Jean-Pierre Féral, Yves Richard, et al.. Recent climate variability around the Kerguelen Islands (Southern Ocean) seen through weather regimes. Journal of Applied Meteorology and Climatology, 2021, 60 (5), pp.711-731. 10.1175/JAMC-D-200255.1 . hal-03235508

\author{
HAL Id: hal-03235508 \\ https://hal.science/hal-03235508
}

Submitted on 25 May 2021

HAL is a multi-disciplinary open access archive for the deposit and dissemination of scientific research documents, whether they are published or not. The documents may come from teaching and research institutions in France or abroad, or from public or private research centers.
L'archive ouverte pluridisciplinaire HAL, est destinée au dépôt et à la diffusion de documents scientifiques de niveau recherche, publiés ou non, émanant des établissements d'enseignement et de recherche français ou étrangers, des laboratoires publics ou privés. 


\title{
Recent Climate Variability around the Kerguelen Islands (Southern Ocean) Seen through Weather Regimes $\mathbb{0}$
}

\author{
Benjamin Pohl, ${ }^{\mathrm{a}}$ Thomas Saucède, ${ }^{\mathrm{a}}$ Vincent Favier, ${ }^{\mathrm{b}}$ Julien Pergaud, ${ }^{\mathrm{a}}$ Deborah Verfaillie, ${ }^{\mathrm{c}}$ \\ JEAN-PIERRE FÉRAL, ${ }^{\mathrm{d}}$ Ylber KRASNIQI, ${ }^{\mathrm{a}}$ AND YVES RICHARD ${ }^{\mathrm{a}}$

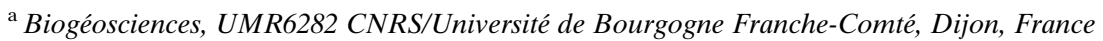 \\ ${ }^{\mathrm{b}}$ Université Grenoble Alpes/CNRS/IRD/G-INP, IGE, Grenoble, France \\ ${ }^{\mathrm{c}}$ Georges Lemaître Centre for Earth and Climate Research, Earth and Life Institute, Université Catholique de Louvain, \\ Louvain-la-Neuve, Belgium \\ ${ }^{\mathrm{d}}$ Aix Marseille Université/CNRS/IRD/Avignon Université, IMBE-UMR7263, Station Marine d'Endoume, Marseille, France
}

(Manuscript received 15 October 2020, in final form 5 April 2021)

\begin{abstract}
Daily weather regimes are defined around the Kerguelen Islands (Southern Ocean) on the basis of daily 500-hPa geopotential height anomalies derived from the ERA5 ensemble reanalysis over the period 1979-2018. Ten regimes are retained as significant. Their occurrences are highly consistent across reanalysis ensemble members. Regimes show weak seasonality and nonsignificant long-term trends in their occurrences. Their sequences are usually short (1-3 days), with extreme persistence values above 10 days. Seasonal regime frequency is mostly driven by the phase of the southern annular mode over Antarctica, midlatitude dynamics over the Southern Ocean such as the Pacific-South American mode, and, to a lesser extent, tropical variability, with significant but weaker relationships with El Niño-Southern Oscillation. At the local scale over the Kerguelen Islands, regimes have a strong influence on measured atmospheric and oceanic variables, including minimum and maximum air temperature, mostly driven by horizontal advections, seawater temperature recorded $5 \mathrm{~m}$ below the surface, wind speed, and sea level pressure. Relationships are weaker for precipitation amounts. Regimes also modify regional contrasts between observational sites in Kerguelen, highlighting strong exposure contrasts. The regimes allow us to improve our understanding of weather and climate variability and interactions in this region; they will be used in future work to assess past and projected long-term circulation changes in the southern midlatitudes.
\end{abstract}

KEYWORDS: Southern Ocean; Antarctic Oscillation; Climate variability; Interannual variability; Southern Oscillation

\section{Introduction}

The Southern Hemisphere (SH) subantarctic region, or the latitudinal band between $45^{\circ}$ and $55^{\circ} \mathrm{S}$, is characterized by strong west-to-east atmospheric circulation with very active cyclogenesis (Befort et al. 2016). The prevailing westerly winds, widely known as the "roaring forties," generate contrasting terrestrial ecosystems and landscapes depending on wind exposure, which strongly conditions the composition and distribution of vegetation types (Bergstrom et al. 2002; Smith and Mucina 2006; McGlone et al. 2019). Extreme moisture and cool conditions on mountain ranges also allow large ice fields and glaciers in Patagonia, New Zealand, and the subantarctic islands to form, even at low altitudes. During the twentieth century, this area experienced major climatic variations and evolutions (Richard et al. 2013), with significant consequences in ecosystems and a dramatic (Dussaillant et al. 2019; Favier et al. 2016) but not ubiquitous (Mackintosh et al. 2017) retreat of ice bodies. Commonly cited as the main causes of these changes are the stratospheric ozone depletion and the increase

Supplemental information related to this paper is available at the Journals Online website: https://doi.org/10.1175/JAMC-D-200255.s1.

Corresponding author: Benjamin Pohl, benjamin.pohl@u-bourgogne.fr in greenhouse gas emissions, which resulted in a multidecadal trend toward the positive phase of the southern annular mode (SAM) since at least the 1960s (Marshall 2003; Renwick 2004; Thompson et al. 2011; Pohl and Fauchereau 2012; Abram et al. 2014).

Considered as the leading mode of climate variability in the southern mid- and high latitudes (i.e., south of $20^{\circ} \mathrm{S}$; Fogt and Marshall 2020), the SAM is characterized by a zonally symmetric dipole in atmospheric pressure, largely controlling mass and momentum exchanges between the mid- and high latitudes (Marshall 2003). During the positive (negative) phase of the SAM, low (high) pressure anomalies over Antarctica are associated with a strengthening (weakening) of the circumpolar vortex and a contraction (expansion) of the westerly wind belt (e.g., Sallée et al. 2008). The SAM has a strong influence on rainfall (e.g., Gillett et al. 2006; Favier et al. 2016) and temperatures (e.g., Manatsa et al. 2013; Lim et al. 2019) at mid- and high latitudes, the Southern Ocean circulation and sea ice concentration (e.g., Sen Gupta and England 2007). It has also a major control on the interannual variability of $\mathrm{CO}_{2}$ fluxes in the Southern Ocean, due to its impact on upwelling (e.g., Lenton and Matear 2007). During the austral summer season, the SAM has been shown to be strongly related to the phase of El Niño-Southern Oscillation (ENSO; e.g., Carvalho et al. 2005; L'Heureux and Thompson 2006; Ciasto and Thompson 2008). L'Heureux and Thompson (2006) estimate that roughly $25 \%$ of the SAM variance linearly relates to the state of ENSO. 


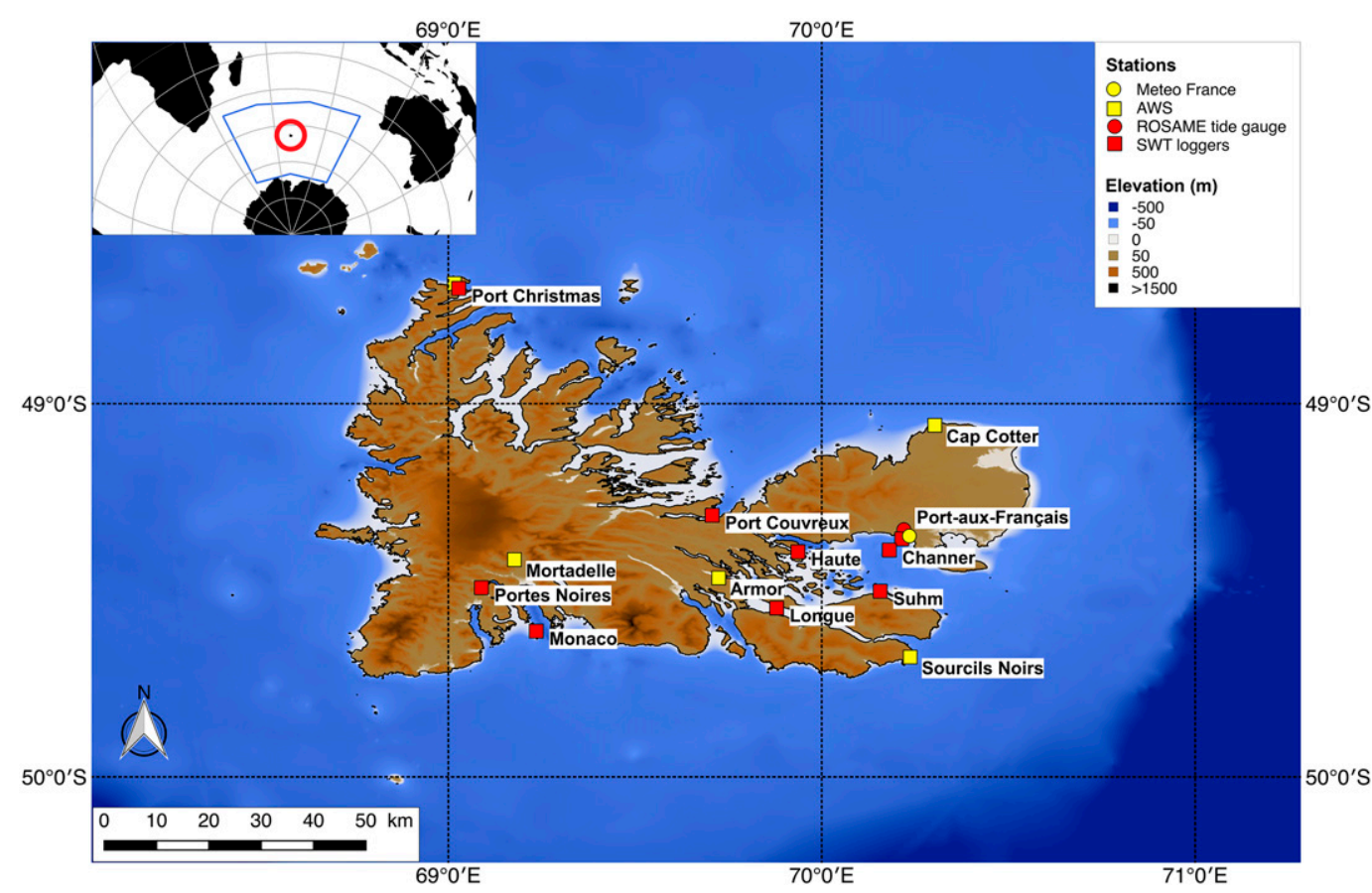

FIG. 1. General presentation of the Kerguelen Islands and local, in situ meteorological observations (Météo France at Port-aux-Français and five AWS) and SST measurements (the ROSAME tide gauge at Port-aux-Français and SWT loggers). The location of the Kerguelen Islands is shown by the red circle in the inset, and the domain used to define the weather regimes is shown outlined in blue therein.

Fogt and Bromwich (2006) more precisely depict significant relationships between these two modes during the $1980 \mathrm{~s}$ and the 1990s for the December-February season, while for September-November significant teleconnections are only apparent during the 1990s. In addition to the SAM, the PacificSouth American 1 and 2 patterns (PSA1 and PSA2), characterized by zonally asymmetric pressure anomalies across the extratropical Pacific Ocean, are also coupled with variations in tropical convection (e.g., Mo and Higgins 1998). Despite its origins in the equatorial Pacific, ENSO influences the southern extratropical and Antarctic climate via teleconnections caused by Rossby wave trains (Turner 2004; Ding et al. 2011) induced by tropical convection anomalies. Such interactions between these modes of climate variability in the SH, linking high latitudes and Antarctica to tropical convection, have major implications for the subantarctic region and the southern midlatitudes. These issues are also of primary importance for future decades under ongoing climate change, since climate projections for the $\mathrm{SH}$, for the late twenty-first century, mostly consist in a farther-southward shift of the storm track following the decadal changes that occurred since the 1960 s (Perlwitz 2011).

Isolated in the southern Indian Ocean, the Kerguelen Islands (Fig. 1) form a particularly relevant natural laboratory to study recent variability and changes in the SAM and more generally in climate of the SH (Favier et al. 2016). There, the multidecadal trends toward the positive phase of the SAM were shown to result in (i) a shift of the storm tracks from Kerguelen to southward locations, (ii) an atmospheric surface pressure increase around Kerguelen, (iii) a drying at Kerguelen and northward, and (iv) an oceanic warming over large areas around Kerguelen since the mid-1970s (Favier et al. 2016). Current 10 -yr mean precipitation is roughly $50 \%$ of what it was in the $1950 \mathrm{~s}$, and warming is $+0.13^{\circ} \mathrm{C} \mathrm{decade}^{-1}$ since then (e.g., Berthier et al. 2009; Verfaillie et al. 2015, 2019; Favier et al. 2016). These recent evolutions contrast with stable conditions observed in the Kerguelen Islands between the 1850 s and 1950s, as revealed by the front positions of the main glacier of the archipelago, Ampere Glacier (Favier et al. 2016). As a primary response to precipitation decrease since the mid-1960s, the glacier loss on the Cook Ice Cap in Kerguelen has been extremely rapid (Berthier et al. 2009; Verfaillie et al. 2015, 2019; Favier et al. 2016). By contrast with the post-Little Ice Age situation, the glacier retreated $2.8 \mathrm{~km}$ (i.e., $18 \%$ in length) between 1963 and 2003 (Berthier et al. 2009) and current ice-cap-wide mass balance (less than $-1.8 \mathrm{~m}$ equivalent water per year between 2000 and 2009) lies within the most negative values worldwide (Verfaillie et al. 2015, 2019; Favier et al. 2016). Glacier modeling demonstrated that $70 \%$ of the current negative mass balance is explained by the drying trend, associated with changes in the storm tracks, while atmospheric warming (resulting from enhanced greenhouse effect driven by anthropogenic emissions) played a smaller amplifying role. This differs from glaciers in other locations of the southern (e.g., Mackintosh et al. 2017; Dussaillant et al. 2019) and northern subpolar latitudes (e.g., Vaughan et al. 2013), where ice wastage is more generally attributed to warming. 
Although the regional influence of the low-frequency circulation changes associated with the SAM and enhanced by climate change have already been documented in and around Kerguelen (Favier et al. 2016), the interactions between such long-term variability and transient climate fluctuations have never been analyzed to date, nor has their combined influence to modulate local weather and climate. These issues are yet important to consider, since scale interactions in the climate system, interacting with the marked topography of the archipelago, could yield major changes in the spatial and temporal distributions of precipitation amounts, as well as water and air temperature. This could in turn lead to deep perturbations in the local ecosystems, both in terrestrial and nearshore environments (Schofield et al. 2010; Byrne et al. 2016; Ullah et al. 2018; Bryndum-Buchholz et al. 2019, among many others). Owing to the very light human presence at Kerguelen, the archipelago can be seen as a sentinel monitoring the effects and impacts of climate variability and change, in the absence of any other local perturbation. A prerequisite task is to establish a comprehensive assessment of climate variability and change there, together with an analysis of large-scale drivers and teleconnections on the one hand, and local effects on the other hand.

This is the gap that the present study proposes to fill. Here, we use daily weather regimes to address these issues, using state-of-the-art ensemble reanalysis (viz., ERA5) to obtain robust synoptic configurations over recent decades (since 1979). Working in the satellite era with an ensemble allowing for detailed uncertainty assessment is strongly needed in this region, given the scarcity of weather observations over the Southern Ocean that poorly constrains reanalyses (e.g., Slivinski et al. 2019).

The aims of the present paper are to

(i) characterize climate variability in and around the Kerguelen Islands through recurrent synoptic-scale atmospheric configurations;

(ii) analyze to what extent these regional-scale configurations are driven by larger-scale modes of climate variability in the $\mathrm{SH}$; and

(iii) assess how these configurations modulate local-scale meteorological variables and perturb spatial contrasts between contrasted sites or regions (e.g., in terms of elevation or exposition) on these islands.

\section{Data and methods}

\section{a. ERA5 reanalysis and in situ observational databases}

Atmospheric fields used in this study are taken from the ERA5 ensemble reanalysis (Copernicus Climate Change Service 2017; Hersbach et al. 2020). ERA5 is the fifth generation of atmospheric reanalysis released by the European Center for Medium-Range Weather Forecasts. It currently covers the period from 1979 onward (with planned extension to 1950 onward) and includes a 10-member ensemble to quantify uncertainties associated with the density and quality of the assimilated data. In this work, we use regular $0.5^{\circ} \times 0.5^{\circ}$ grids of daily fields of the following variables: shortwave surface solar radiation $\left(\mathrm{SSR} ; \mathrm{W} \mathrm{m}^{-2}\right)$, total water column $\left(\mathrm{kg} \mathrm{m}^{-2}\right)$, total cloud cover (fraction), air temperature at $2 \mathrm{~m}$ above the surface $\left(\mathrm{T} 2 \mathrm{~m} ;{ }^{\circ} \mathrm{C}\right)$, horizontal wind $\left(\mathrm{m} \mathrm{s}^{-1}\right)$ and relative humidity $\left(\mathrm{g} \mathrm{kg}^{-1}\right)$ at $850 \mathrm{hPa}$, vertical velocity of the wind at 850 and $500 \mathrm{hPa}\left(\mathrm{Pa} \mathrm{s}^{-1}\right)$, and geopotential height at $700\left(Z_{700}\right)$ and $500\left(Z_{500} ; \mathrm{m}\right) \mathrm{hPa}$.

A daily SAM index is used to assess relationships between the Kerguelen regimes and the state of the climate in the SH. Here, the observation-based index of Marshall (2003) is chosen, since it avoids spurious trends often found in reanalysesbased SAM indices. This index is available since 1957 and computed as the mean atmospheric pressure differences between "high latitudes" (stations located between $50^{\circ}$ and $70^{\circ} \mathrm{S}$ ) and "midlatitudes" (stations between $30^{\circ}$ and $50^{\circ} \mathrm{S}$ ).

The state of ENSO is monitored by a regional sea surface temperature (SST) index averaged spatially over the Niño-3.4 region $\left(5^{\circ} \mathrm{N}-5^{\circ} \mathrm{S}, 170^{\circ}-120^{\circ} \mathrm{W}\right)$. Here, we chose the most commonly used index, derived from the HadISST database (Rayner et al. 2003) and available since 1870 at a monthly time step.

Global SST fields $\left({ }^{\circ} \mathrm{C}\right)$ are taken from the ERSST v5 database (Huang et al. 2017) available at a monthly time step on a $2^{\circ} \times 2^{\circ}$ global grid. This product, suited for long-term and largescale studies, is used here to analyze global teleconnections with our regimes. It offers robust estimations of basinwide or global patterns but smooths local features and should therefore not be compared with local seawater temperature (SWT) measurements performed at Kerguelen.

These large-scale datasets are completed by local in situ observations performed at various locations on the Kerguelen Islands (Figs. 1 and 2). The longest time series are available at the main technical and scientific station of the Kerguelen Archipelago, namely, Port-aux-Français. Daily atmospheric observations are performed by Météo-France, the French weather services, at a synoptic weather station that participates in the world weather watch. Records are available since January 1951, and thus, over the whole study period. Monitored variables are daily minimum $(\mathrm{Tn})$ and maximum $(\mathrm{Tx})$ air temperature $\left({ }^{\circ} \mathrm{C}\right)$, daily precipitation amounts $(\mathrm{mm})$, mean sea level pressure $(\mathrm{hPa})$, relative humidity $(\%)$, global surface radiation $\left(\mathrm{J} \mathrm{cm}^{-2}\right)$, and wind speed $\left(\mathrm{m} \mathrm{s}^{-1}\right)$ and direction (wind rose; $\left.{ }^{\circ} \mathrm{N}\right)$. The present study makes use of all of them, except for wind direction. We use the temperature time series to calculate the diurnal thermal range (DTR) defined as the daily difference between Tx and Tn.

Additionally, data from five meteorological stations distributed over the archipelago were used to depict regional characteristics of meteorological settings. The automatic weather stations (AWS) installed at Mortadelle, Port Christmas, Cap Cotter, Sourcils Noirs, and Armor sites make it possible to document daily temperature, humidity, wind speed, and direction, and precipitation. The Mortadelle station was installed in December 2010 (Verfaillie et al. 2015), whereas other stations were set up in January and February 2012 (Verfaillie et al. 2019). Precipitations in Port Christmas may be perturbed by a lake near the station and should therefore be considered with greater caution.

Nearshore SWT has been measured at the Service National d'Observations (SNO) Réseau d'Observation Sub-antarctique et Antarctique du Niveau de la Mer (ROSAME) network tide gauge of Port-aux-Français since 1993. Measurements were 

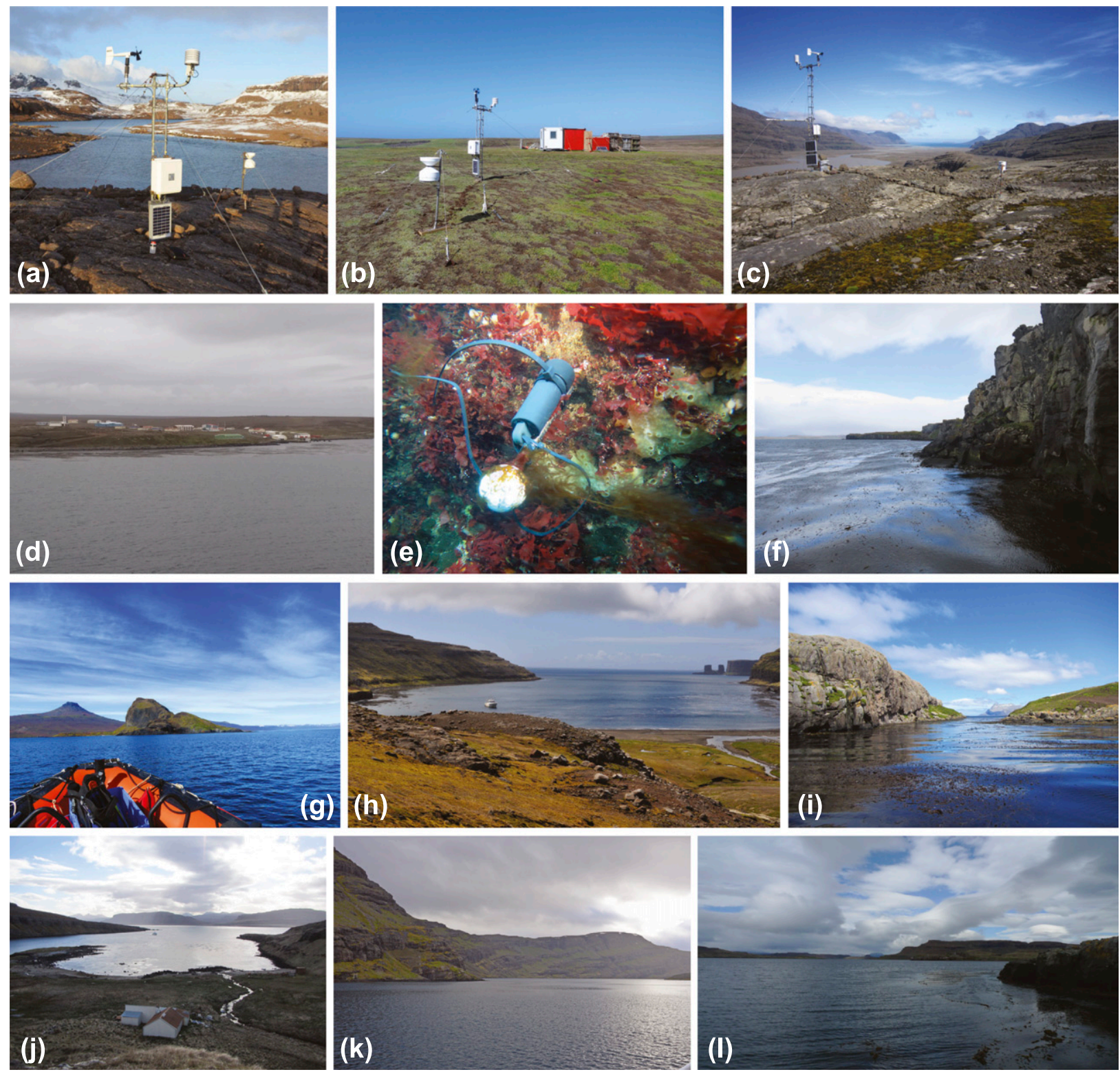

FIG. 2. Observational networks for atmospheric [in (a)-(d)] and subsurface oceanic [in (d)-(l)] monitoring deployed at Kerguelen: AWS of (a) Armor, (b) Cap Cotter, and (c) La Mortadelle; (d) the Port-aux-Français main station; (e) data loggers for SWT measurements; and sites for SWT measurements of (f) Longue, (g) Suhm, (h) Port Christmas, (i) Monaco, (j) Port Couvreux, (k) Portes Noires, and (l) Haute. All photographs were taken by the authors, except (h), which is by D. Rolland.

performed at an hourly time step until 2013 and were doubled with a second sensor measuring temperature every 2 min since 2006. Over their common period, both series are very similar. In 2015, maintenance work led to a nearly one-year-long gap in the time series. In this work, we concatenated and resampled the whole series at a daily time step over the 1993-2018 period. Local hydrographic measurements were completed by data from a network of HOBO Pro v2 loggers (Fig. 2e) set up at nine sites along the shore of the archipelago, at Port-aux-Français, Channer, Haute, Suhm, and Longue islands in the Morbihan Bay in the east, Port Christmas and Port Couvreux (îlot des
Trois Bergers) to the north, Fjord des Portes Noires and Prince de Monaco islands in the south (Figs. 1 and 2). Temperature loggers were attached to the substratum at about 5-m depth, and SWT measurements were performed at an hourly time step since 2012. Measurement precision and drift, tested for each logger over two years, are less than $\pm 0.1^{\circ} \mathrm{C}$ (Féral et al. 2016).

\section{b. The k-means clustering algorithm}

Daily weather regimes are obtained through a $k$-means clustering (Cheng and Wallace 1993; Michelangeli et al. 1995). 


\begin{tabular}{|c|c|c|c|c|c|c|c|c|c|c|c|}
\hline & \multicolumn{10}{|c|}{ Day $_{i}$} \\
\hline & & 1 & 2 & 3 & 4 & 5 & 6 & 7 & 8 & 9 & 10 \\
\hline \multicolumn{2}{|c|}{ Size } & $1328 \pm 3$ & $1750 \pm 3$ & $1156 \pm 2$ & $1489 \pm 2$ & $1150 \pm 4$ & $1896 \pm 3$ & $1310 \pm 3$ & $1341 \pm 2$ & $1704 \pm 4$ & $1470 \pm 4$ \\
\hline \multirow{10}{*}{ 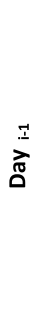 } & 1 & $548 \pm 3$ & $100 \pm 1$ & $399 \pm 1$ & 3 & 0 & 3 & 13 & $16 \pm 1$ & $116 \pm 1$ & $128 \pm 1$ \\
\hline & 2 & $62 \pm 1$ & $893 \pm 2$ & $106 \pm 2$ & $266 \pm 1$ & 1 & $178 \pm 2$ & $62 \pm 1$ & 1 & $101 \pm 1$ & 76 \\
\hline & 3 & 24 & $154 \pm 2$ & $415 \pm 2$ & $254 \pm 2$ & 2 & $40 \pm 1$ & 45 & 1 & 28 & $189 \pm 2$ \\
\hline & 4 & 1 & $96 \pm 1$ & 4 & $712 \pm 2$ & $197 \pm 1$ & $261 \pm 2$ & $188 \pm 2$ & 2 & 5 & 22 \\
\hline & 5 & 0 & 0 & 1 & 20 & $493 \pm 2$ & $162 \pm 2$ & $145 \pm 1$ & $291 \pm 1$ & 8 & $26 \pm 1$ \\
\hline & 6 & 14 & $174 \pm 1$ & 7 & $62 \pm 1$ & $149 \pm 2$ & $817 \pm 2$ & $146 \pm 1$ & $144 \pm 2$ & $301 \pm 1$ & $78 \pm 1$ \\
\hline & 7 & $150 \pm 1$ & $185 \pm 2$ & $137 \pm 1$ & $67 \pm 1$ & 13 & $48 \pm 1$ & $529 \pm 4$ & $32 \pm 1$ & $77 \pm 1$ & $68 \pm 1$ \\
\hline & 8 & $253 \pm 1$ & $6 \pm 1$ & 15 & 0 & 15 & $28 \pm 1$ & $79 \pm 1$ & $595 \pm 2$ & $228 \pm 1$ & $119 \pm 1$ \\
\hline & 9 & $259 \pm 1$ & $122 \pm 1$ & $49 \pm 1$ & 5 & 2 & $132 \pm 1$ & 22 & $101 \pm 1$ & $779 \pm 5$ & $229 \pm 2$ \\
\hline & 10 & 15 & 18 & 19 & $98 \pm 2$ & $274 \pm 2$ & $224 \pm 2$ & $76 \pm 1$ & $155 \pm 1$ & $58 \pm 1$ & $528 \pm 3$ \\
\hline
\end{tabular}

FIG. 3. Transition (for the period 1979-2018) between regimes and regime size. In each cell, the first figure is the ensemble mean and gray figures denote the intermember standard deviation, with \pm 0 omitted for readability. Light-blue shadings are transitions that concern $<5 \%$ of the days of the regime of day $i$. Yellow shadings are transitions that concern $>25 \%$ of the days of the regime of day $i$. Green shadings are self-transition (regimes followed by themselves).

This algorithm, often used in climate sciences, has already been successfully used to decompose synoptic-scale meteorology in the SH at subtropical (Fauchereau et al. 2009; Pohl et al. 2018) or high latitudes (Richard et al. 2013), or to analyze the longterm changes in the southern annular mode over Antarctica and the Southern Ocean (Pohl and Fauchereau 2012). It is here applied for the first time to the region around the Kerguelen Islands, that is, at the middle latitudes of the $\mathrm{SH}$ where dominant westerly fluxes prevail throughout the year. A similar application was used at similar latitudes over New Zealand (Kidson 2000).

The $k$-means clustering is used to determine regional-scale atmospheric configurations that could drive local-scale weather conditions, and that could potentially be controlled themselves by large-scale background climate conditions. In the middle latitudes, such configurations are usually monitored through geopotential height. Thus, the $k$-means clustering is applied here to $Z_{500}$ anomalies (i.e., after removing the mean annual cycle) taken from the first member of the ERA5 reanalysis on the period 1 January 1979-31 December 2018 (i.e., 40 years of daily regimes) over the domain $35^{\circ}-65^{\circ} \mathrm{S}$ and $35^{\circ}-105^{\circ} \mathrm{E}$ (i.e., $61 \times 141=8601$ grid points at a $0.5^{\circ}$ spatial resolution), which is centered on the Kerguelen Islands. This domain is chosen to match the typical size of synoptic perturbations and thus encompasses most of the disturbances that propagate in the midlatitudes over this sector.

A principal component analysis is applied to these $Z_{500}$ anomalies prior to the $k$-means clustering to filter out atmospheric noise. The PCA-filtered $Z_{500}$ anomalies account for $80 \%$ of the original variance in five eigenvectors. Following Michelangeli et al. (1995), the optimal number of clusters $k$ is determined using a red noise test, which compares the "classifiability" of real input data with Markov-generated red noise data having the same covariance matrix. Results (Fig. 1 in the online supplemental material) reveal that partitions into 9 and 10 regimes are the only ones that reach systematically the 95\% significance bound, whatever their initial random draws. Partitions into 10 regimes are finally retained, since they perform generally better (not shown).
To quantify intermember uncertainties, the regimes are next calculated for the other members of the ERA5 ensemble. The daily $Z_{500}$ anomalies from these members are first projected onto the phase space described by the first five eigenvectors of member 1. Second, the Euclidean distance $d$ between each observation (i.e., each day of each member) and each of the $k=10$ centroids of member 1 is computed, and each observation is assigned to the closest centroid by minimizing $d$. Already used in Crétat et al. (2015) and Pohl et al. (2018), this projection method forces the regimes to have similar spatial patterns across the members but does not impose any temporal covariability: this facilitates discussion of the temporal uncertainties in the ensemble, seen through disagreements in regime occurrence.

\section{Results}

\section{a. Analysis of the weather regimes}

All 10 regimes have comparable sizes over the 40 years of the study period (Fig. 3), a result that is partly due to the mathematical formulation of the $k$-means algorithm. The largest regime (6: about 1900 days) includes roughly $65 \%$ more days than the smallest ones ( 5 and 3: about 1150 days each). From one ERA5 member to another, the regime size appears very similar, thus indicative of very weak uncertainties.

The time distribution of the regimes is shown in Fig. 4, together with associated uncertainties in the ERA5 ensemble. About $96.9 \%$ of the days of the period are ascribed to the same regime for the 10 members (and $98.8 \%$ of the days ascribed to the same regime for at least 8 members of 10), denoting very strong reproducibility in the ensemble. This result is probably due to the input field $\left(Z_{500}\right)$ of the $k$-means clustering, which is generally very smoothed and highly spatially coherent. Yet, one can note slightly larger uncertainties during the first years of the period, prior to the late 1990s, possibly due to the introduction of active sensors on meteorological satellites in this period.

The distribution of the regimes over the period (Fig. 4, bottom) shows no clear seasonality, as confirmed by the bars in 

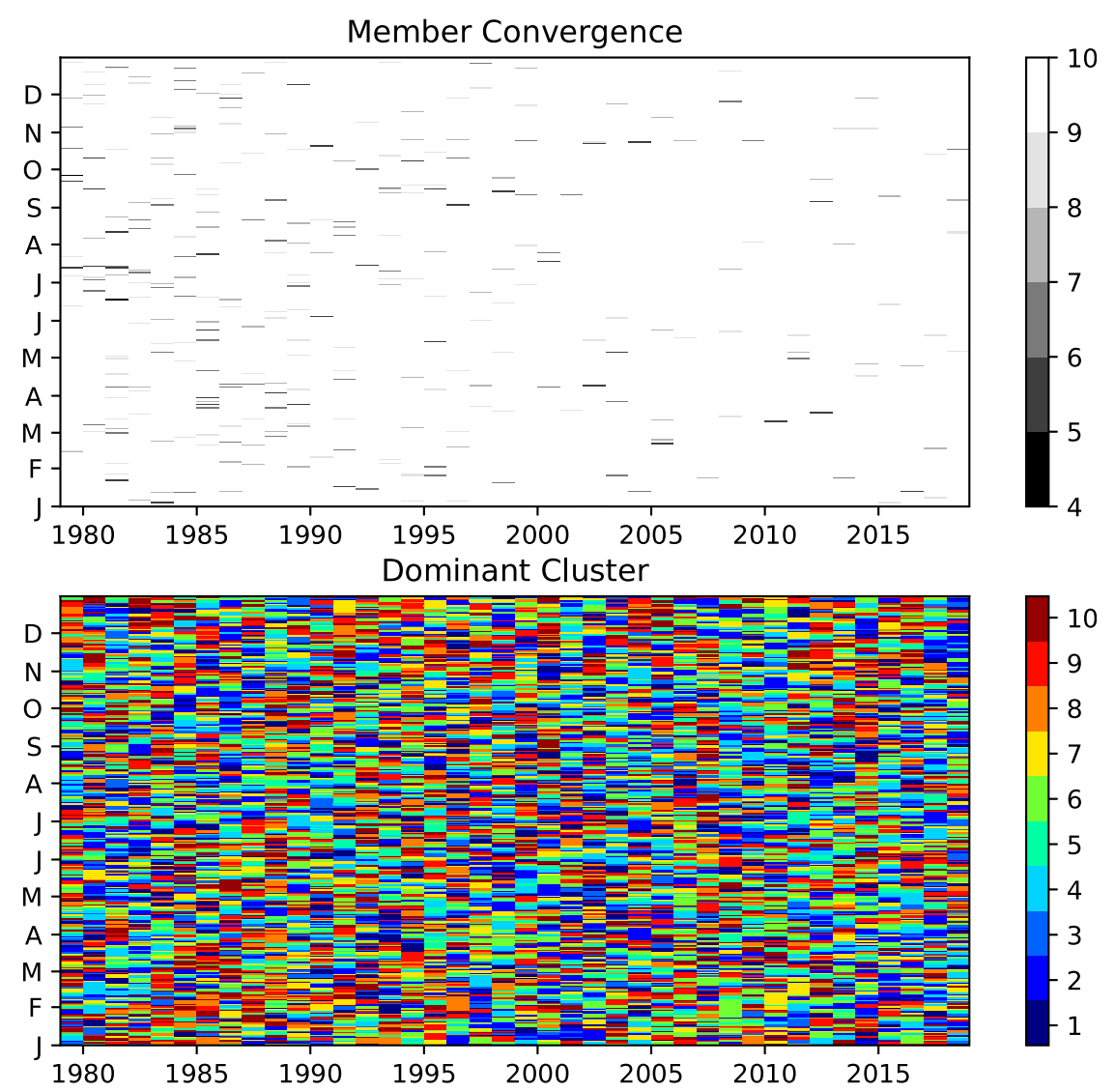

FIG. 4. Calendar of the weather regimes, and associated uncertainties, for all days ( $y$ axis) of the 1979-2018 study period ( $x$ axis). (top) Number of members (of 10) of ERA5 ascribed to the same regime. (bottom) Dominant regime of each day (i.e., regime at which the largest number of members are ascribed).

Fig. 5, and none of the regimes present significant low-frequency signals, that is, either an increasing or a decreasing trend (Fig. 2 in the online supplemental material). Yet, large-scale atmospheric dynamics shows clear and major changes over the twentieth century, mostly consisting in a southward shift of the midlatitude circulation and a poleward expansion of the tropical Hadley circulation (Thompson and Solomon 2002; Marshall 2003; Renwick 2004; Arblaster and Meehl 2006; Son et al. 2008; Perlwitz 2011; among many others). We hypothesize that the period considered here is both too short and too recent to clearly depict these trends and changes, as already suggested, for example, by Pohl and Fauchereau (2012) at the hemispheric scale. This is also consistent with Favier et al. (2016), who identified 1975 as a turning point for Kerguelen, with changes in the teleconnections between the region and large-scale hemispheric dynamics. Another hypothesis is that long-term changes could modify the regimes' internal properties (including their anomaly patterns, either in terms of associated air temperature under increasing greenhouse effect, or atmospheric dynamics, as a consequence of lowfrequency changes in the atmospheric circulation). These issues will be addressed in future work, over longer time periods.
The flat seasonal distribution of the regimes can be partly explained by the fact that they are based on deseasonalized anomalies of $Z_{500}$. Yet, these results indicate that the same spatial anomaly patterns can be found around Kerguelen throughout the year, with similar probability on average from one month to another. Large year-to-year variability is nonetheless found in the regime occurrences (Fig. 5; Fig. 2 in the online supplemental material). Both points are further discussed below.

Figures 6 and 7 show the atmospheric anomaly patterns associated with the 10 regimes. Since regime numbers are randomly determined by the algorithm, we reordered them to have a general eastward propagation of anomaly patterns. Regimes are based on $Z_{500}$ anomalies (colors in Fig. 6) so that this field is, by construction, well differentiated from one regime to another. Synchronous anomalies on other atmospheric fields are then computed to allow for a more exhaustive description and understanding of the synoptic structures associated with the $Z_{500}$ regimes.

Regime 1 is characterized by high pressure/anticyclonic anomalies in the western part of the domain, and low pressure/cyclonic anomalies farther east (Fig. 6). The longitudinal distance between both centers of action is of $40^{\circ}$, corresponding to 

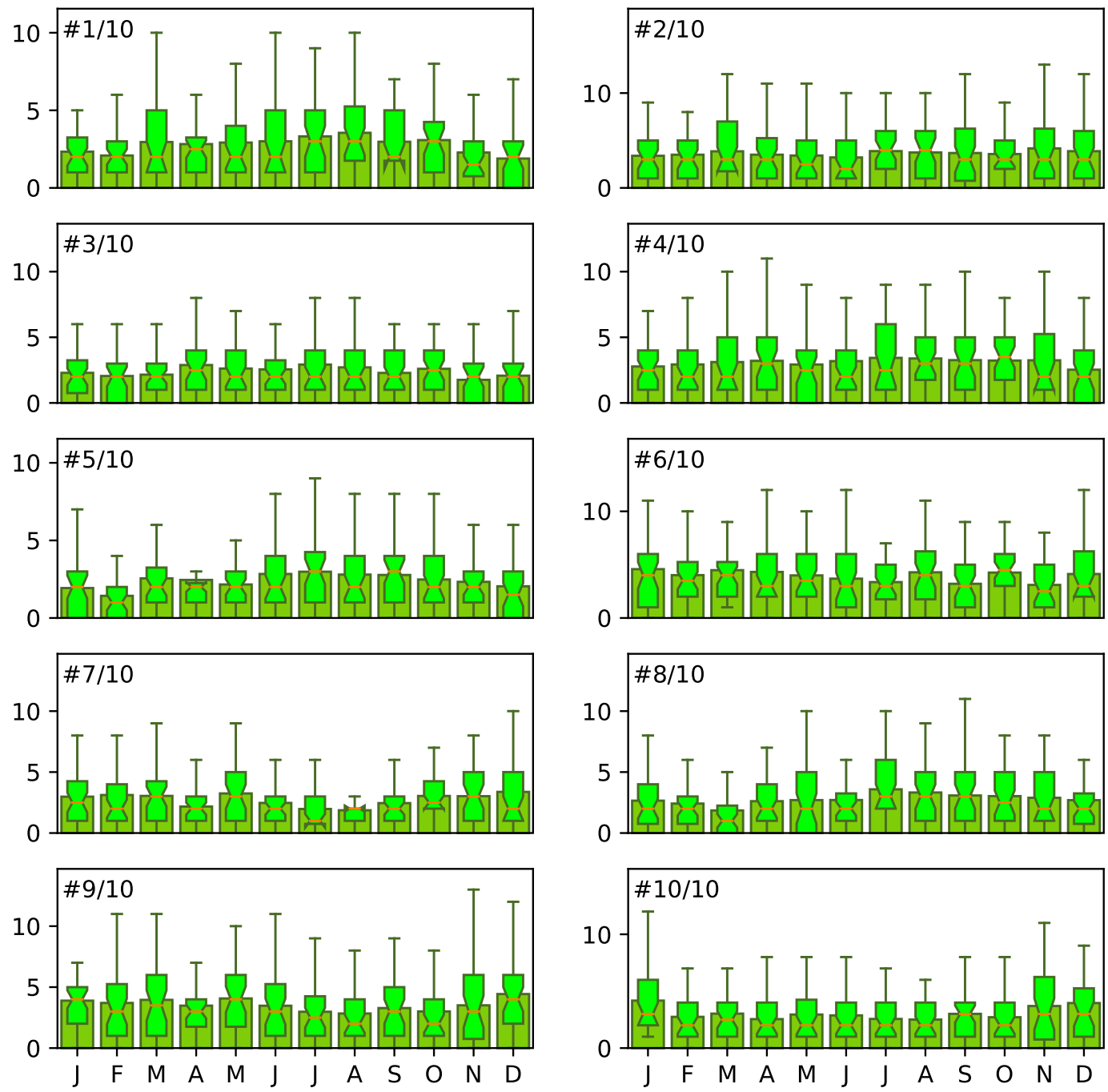

FIG. 5. Regimes' seasonality and interannual variability. Bars: number of mean monthly occurrences of each regime, averaged over the period 1979-2018. Boxplots: spread in the seasonal occurrences of each regime over the 40 years of the period. The boxes have outer lines at the first and third quartiles. The middle lines correspond to the median, and the notches show the uncertainty in the median position due to sample size. The whiskers are lines showing the whole spread of the statistical distributions, with horizontal segments corresponding to the extreme values.

wavenumber 4-5 structures typically associated with midlatitude synoptic disturbances like atmospheric Rossby waves. Wind anomalies being mostly geostrophic, southerly anomalies are found in the central longitudes of the domain, near and over Kerguelen. Associated SSR anomalies (Fig. 7) are shifted westward relative to the high and low pressure centers of action: negative (positive) SSR anomalies are found west of the anticyclonic (cyclonic) anomalies. This is due to (i) the threedimensional structure of midlatitude cyclones, with upward motion on their eastern flank and downward motion to the west (Figs. 8 and 9 in the online supplemental material); and (ii) perturbations in specific humidity induced by meridional wind anomalies, with northerly anomalies favoring humidity export from the low to the midlatitudes (supplemental Fig. 9). This favors atmospheric instability leading to increased cloud cover (supplemental Fig. 8) and negative SSR anomalies, while southerly anomalies advect dry air from the high latitudes under more stable conditions, leading to clear-sky conditions and positive SSR anomalies (Fig. 7; supplemental Figs. 8 and 9). T2m anomalies (Fig. 6) are primarily driven by advections, that is, atmospheric dynamics, rather than radiative anomalies. Despite stronger shortwave radiation, southerly anomalies advecting cold, dry air are associated with marked negative $\mathrm{T} 2 \mathrm{~m}$ anomalies, while the opposite situation holds for northerly anomalies yet accompanied by enhanced cloud cover.

This general picture, as obtained with regime 1, is generally verified for all regimes: wind anomalies are mostly geostrophic and $\mathrm{T} 2 \mathrm{~m}$ is essentially controlled by advective effects. Southerly (northerly) flux anomalies prevail east (west) of anticyclonic patterns, and west (east) of cyclonic ones. The regional atmospheric 


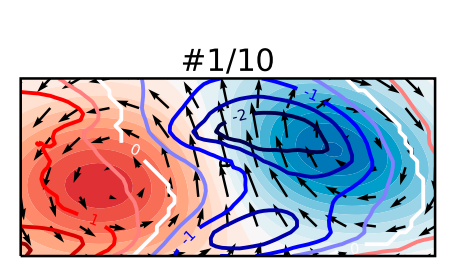

\#3/10

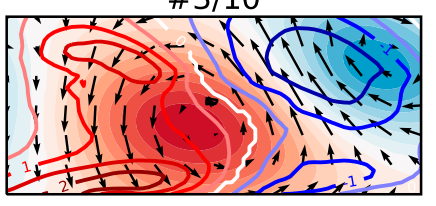

\#5/10

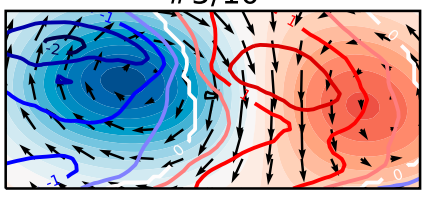

\#7/10

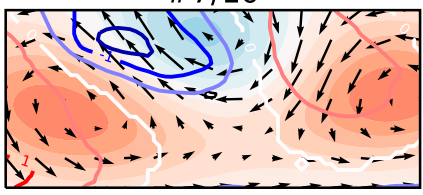

\#9/10

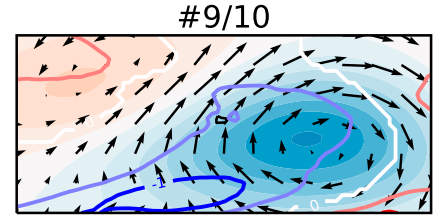

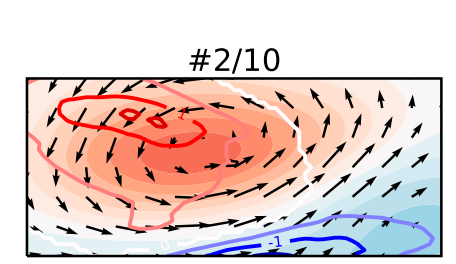

\#4/10

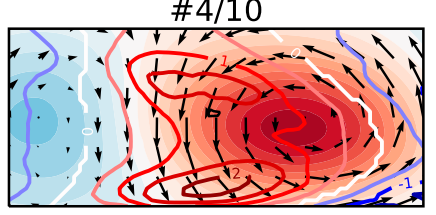

\#6/10

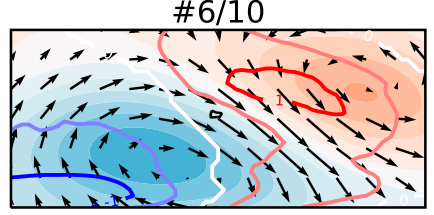

\#8/10

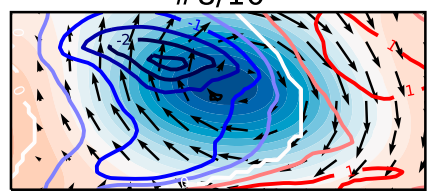

\#10/10

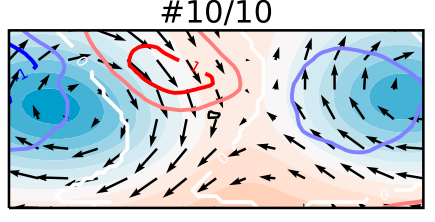

$\rightarrow 5 \mathrm{~m} / \mathrm{s}$

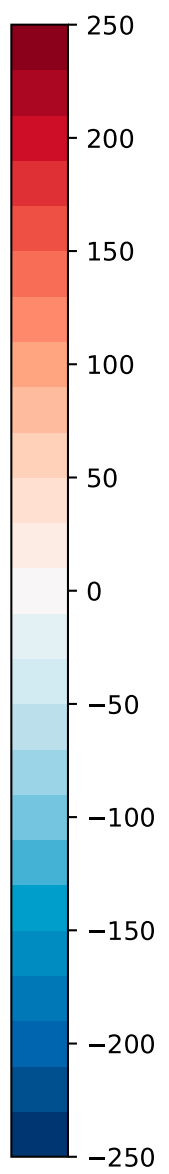

FIG. 6. Anomaly patterns associated with the 10 weather regimes for the period 1979-2018. Shadings: $Z_{500}$ anomalies (m; see the color legend). Vectors: synchronous anomalies of the horizontal wind at $850 \mathrm{hPa}\left(\mathrm{m} . \mathrm{s}^{-1}\right)$. See the arrow key at the upper right for the vector scale. Contours: synchronous temperature anomalies at $2 \mathrm{~m}$ above the surface $\left({ }^{\circ} \mathrm{C}\right)$. Contour interval is $0.5^{\circ} \mathrm{C}$. For all variables, anomalies that are not significantly different from the mean climatology according to a $t$ test at the $95 \%$ confidence level are shaded white or omitted.

circulation adjusts to the location of both types of centers of action. The regimes differentiate from one another in terms of absolute and relative locations of the positive $Z_{500}$ /anticyclonic anomalies, against negative $Z_{500}$ /cyclonic center of action. Taken together, they depict the time and space alternation between both types of anomalies, possibly embedded in wave trains. Regimes 2, 8, and, to a lesser extent, 9 are particular in that they are mostly composed, over the domain, of a single anticyclonic (2) or cyclonic (8-9) center of action, potentially denoting atmospheric configurations of larger spatial scales/lower wavenumbers (e.g., Cash et al. 2002; Kushner and Lee 2007; Pohl and Fauchereau 2012). Associations with larger-scale climate features and modes are considered below. In contrast, regimes 7 and 10 present two successive centers of action of the same sign (anticyclonic for 7 and cyclonic for 10) and associated with lower wavelengths (wavenumber 6-7) that do not correspond to the typical synoptic activity prevailing at these latitudes. Transitions between regimes (Fig. 3) confirm the tendency for successive or similar regimes to follow each other (e.g., 9 to 10,1 to 3 , or 4 to 6 ), further confirming the hypothesis of eastward-propagating, short-lived synoptic structures. Largest values are clearly for self-transitions, suggesting some persistence in the regime sequences. The latter is yet moderate, most regime sequences being rather short (Fig. 4), hereby indicating that the regimes primarily correspond to synoptic-scale configurations. Detailed analysis of regime persistence (Fig. 3 in the online supplemental material) reveals that $50 \%$ of the sequences last only one day for almost all regimes, but they are also all likely to show a few persisting sequences of 8-10 days (the longest sequence being 15 consecutive days for regime 6). Regime persistence shows weak changes between the summer and winter seasons (supplemental Fig. 3).

Depending on the position of these synoptic systems around Kerguelen, contrasted and highly variable synoptic wind anomalies take place near and over these islands: northerly (regimes 4-5), northwesterly $(6,10)$, westerly $(2)$, easterly $(7)$, or southerly $(1,9)$. Finally, regimes 3 and 8 are associated with weak anomalies locally. Consistency or disagreements between 
\#1/10

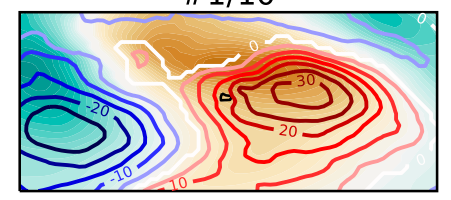

\#3/10

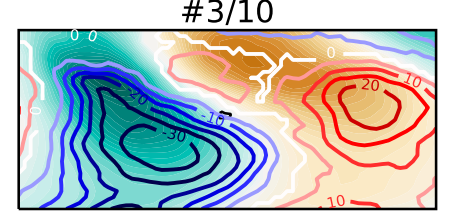

\#5/10

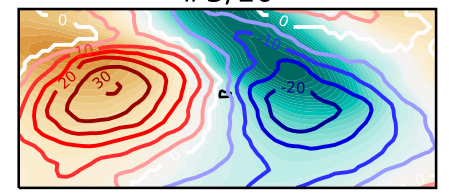

\#7/10

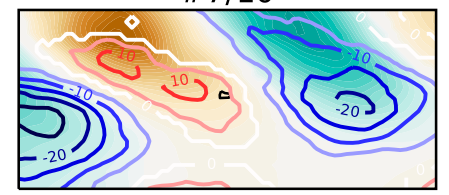

\#9/10

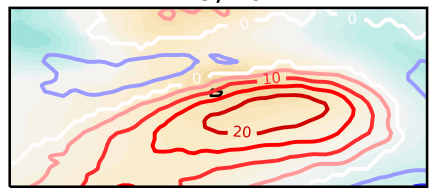

\#2/10

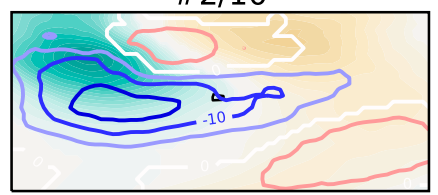

\#4/10

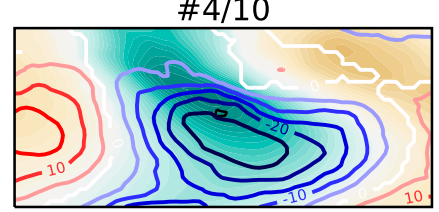

\#6/10

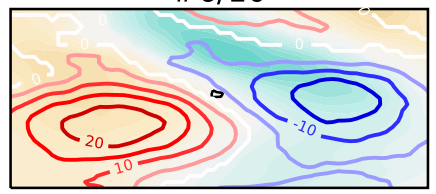

\#8/10

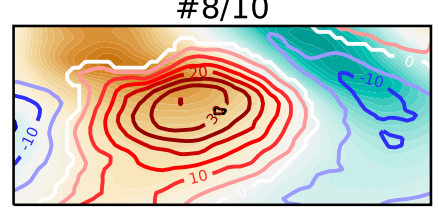

\#10/10

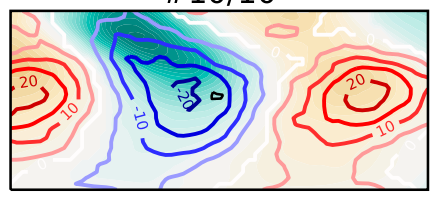

1.5

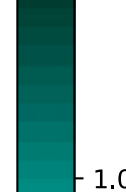

$-0.5$

0.0

$-1.0$

FIG. 7. As in Fig. 6, but for synchronous anomalies of 850 -hPa specific humidity $\left(\mathrm{g} \mathrm{kg}^{-1}\right.$; see the color legend) and shortwave surface solar radiation $\left(\mathrm{W} \mathrm{m}^{-2}\right.$; contours).

reanalyses and in situ observations are analyzed and discussed in section 3c.

Since the anomaly patterns discussed above are nearly equiprobable throughout the year (Fig. 5, Fig. 2 in the online supplemental material), it may seem important to assess to which extent the regimes differ (or not) when extracted only during specific seasons. We calculated therefore their composite anomaly fields over the most contrasted periods of the year, namely austral summer [November-February (NDJF)] and winter [June-September (JJAS)]. Analyses reveal remarkably stable spatial patterns, albeit with different amplitudes (Figs. 4-7 in the online supplemental material): centers of action have similar extensions and locations but atmospheric dynamics (and associated wind, geopotential, and T2m anomalies) is systematically stronger in winter. Quite logically, however, specific humidity and SSR anomalies are much stronger in summer.

\section{b. Interannual variability and large-scale drivers}

Regime occurrence is strongly variable from one year to another (Fig. 5; Fig. 2 in the online supplemental material). In this section, we investigate the mechanisms responsible for such variability, focusing on large-scale climate conditions that could modulate regime frequency at the regional and synoptic scales. To that end, we compute the teleconnections between regime occurrence and SST fields at the global scale (Fig. 8), and $Z_{700}$ in the SH (Fig. 9). These fields are chosen to characterize the state of the climate system at large scales, including tropical and polar modes of variability-all likely to influence the climate around Kerguelen-the midlatitudes corresponding to the location of the sharpest gradients and contrasts between tropical and polar air masses (Pohl and Fauchereau 2012) but also to the subantarctic and polar oceanic fronts (Favier et al. 2016). We present here only the austral summer season, although analyses are duplicated for the winter season as well (Figs. 10 and 11 in the online supplemental material).

Almost all regimes show significant associations with SST anomalies in the SH (Fig. 8), especially at the midlatitudes (except for regime 3 and 5). Relationships are particularly marked around and close to the Kerguelen Islands. Generally, regimes with predominant cyclonic anomalies (regimes 6, 8, 9, and 10) over that region tend to be more frequent under cold SST conditions in the southern midlatitudes. The reverse is found for anticyclonic regimes (2 and 4). Associated SST signals show some zonal symmetry over the Southern Ocean, at least for longitudes corresponding to the Atlantic and Indian 

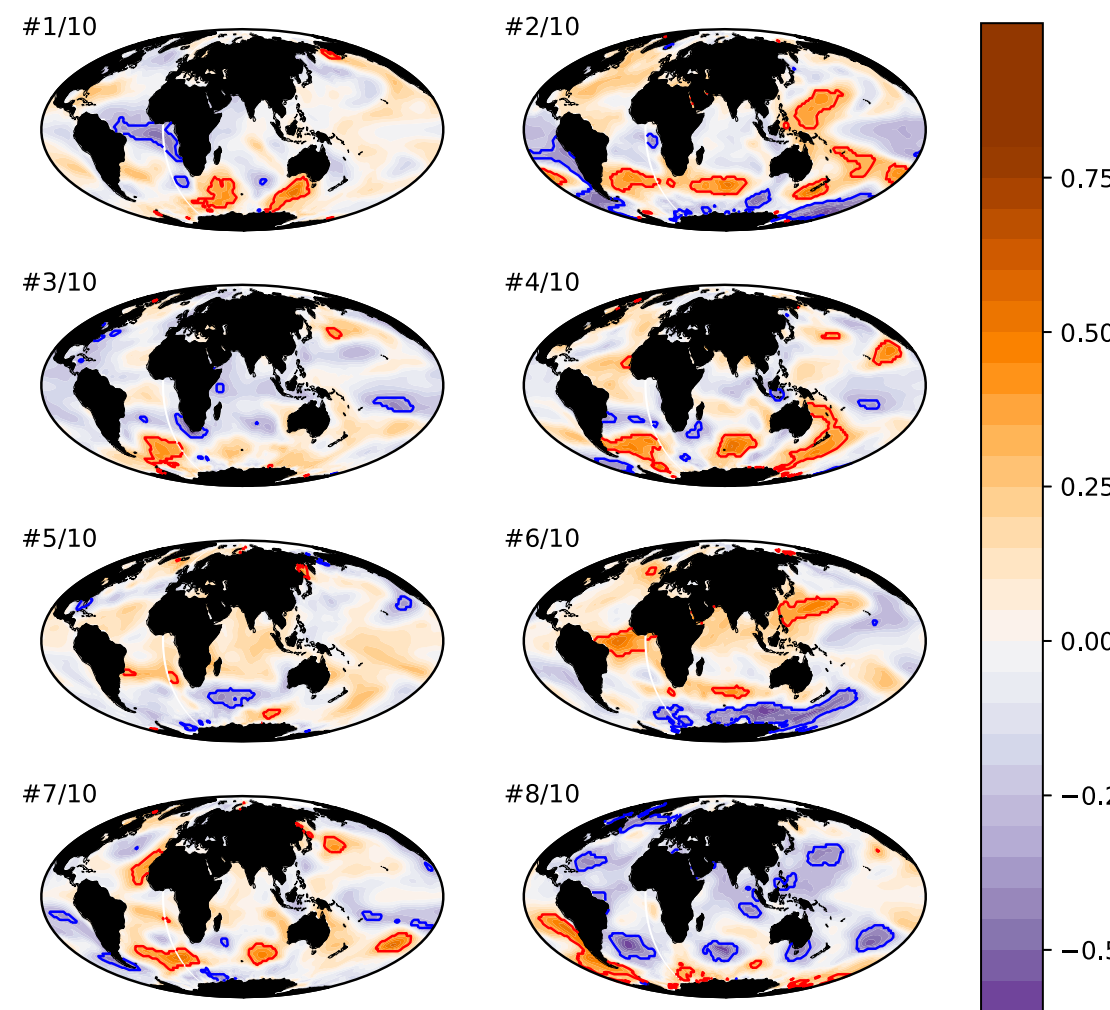

0.75
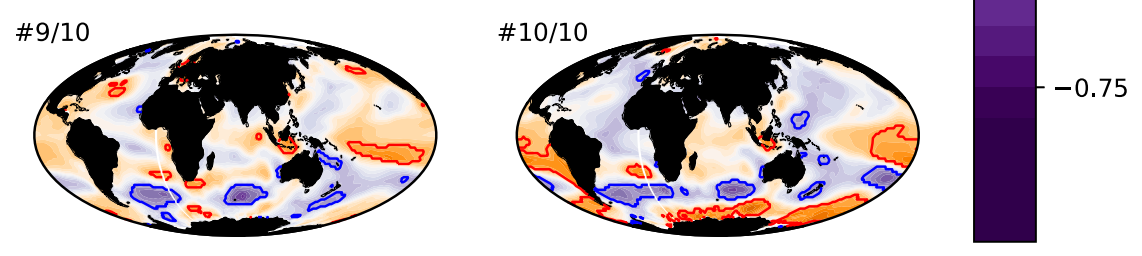

FIG. 8. Teleconnections between the clusters and global SST. Linear correlations between the austral summer (NDJF) seasonal number of occurrences of each cluster and the seasonal mean SST fields for the period from 1979/80 to 2017/18. Solid red and blue lines show positive and negative correlations, respectively, that are significant at the $95 \%$ confidence level according to a Bravais-Pearson test, with a 5\% false discovery rate (Benjamini and Yekutieli 2001) considered for field significance assessment.

sectors. Farther north, associations between regimes and SST variability are generally weaker. Some regimes tend to show relationships with the west Pacific (regimes 2, 8, 9, and 10) or the tropical Atlantic (regimes 1 and 6).

An important feature to consider for the NDJF season is that high latitudes in the $\mathrm{SH}$ tend to be connected with tropical variability, mostly through a significant relationship linking the SAM to the state of ENSO (Carvalho et al. 2005; L'Heureux and Thompson 2006; Ciasto and Thompson 2008). To address this, we recalculated the same teleconnection but after removing ENSO influence. This is achieved first through a linear regression with the seasonal mean Niño-3.4 index, and next through a computation of the correlations with residual SST variability. Results (not shown) are very similar to Fig. 8, suggesting that ENSO is not the main driver of the relationships found here. The same analysis performed after removing SAM influence [as inferred by the SAM index of Marshall (2003)] reveals a drastic weakening of the teleconnections found for regimes 2 and 10 (not shown), hereby suggesting that the SAM has significant influence on the regimes.

Figure 9 aims at estimating SAM influence through teleconnections calculated with the seasonal mean $Z_{700}$ south of $20^{\circ} \mathrm{S}$, considered as a robust field to document the state of the climate in the SH (e.g., Carvalho et al. 2005; Reason and Rouault 2005; L'Heureux and Thompson 2006; Hendon et al. 2007; Pohl et al. 2010). Regimes 2 and 6 present strong relationships with the positive phase of the SAM, as shown by the typical signature of this mode and its dramatic weakening after removal of the SAM variability in the SH. Symmetrically, regime 10 presents an equally strong association with the negative phase of the SAM. The same teleconnections calculated after removing ENSO influence are very similar, confirming that the partial collinearity between ENSO and SAM are not responsible for these significant results (not shown).

Connections with regional-scale $Z_{700}$ features are also found for some regimes, mostly close to the Kerguelen Islands 

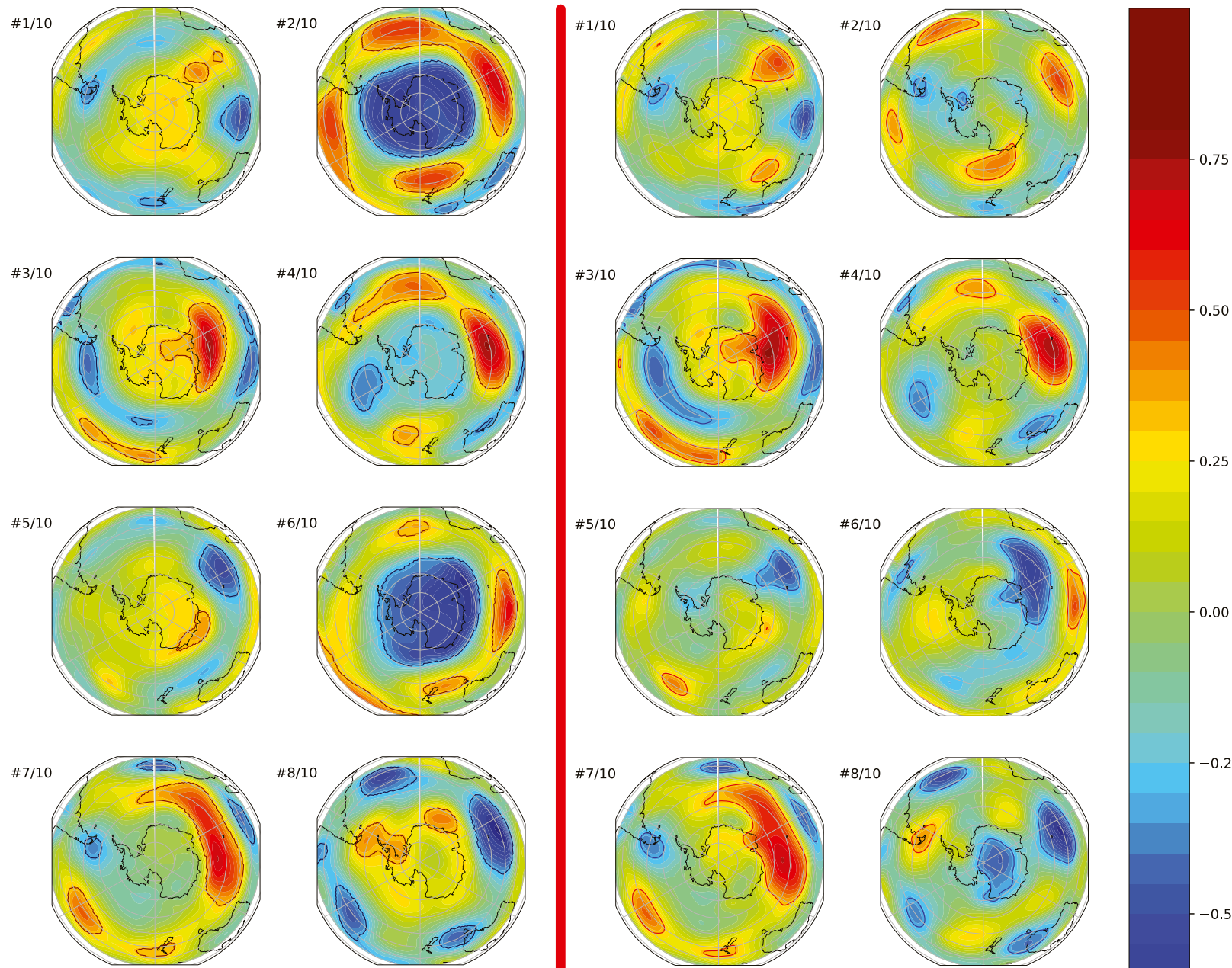

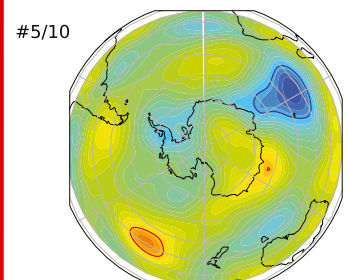

$\# 7 / 10$
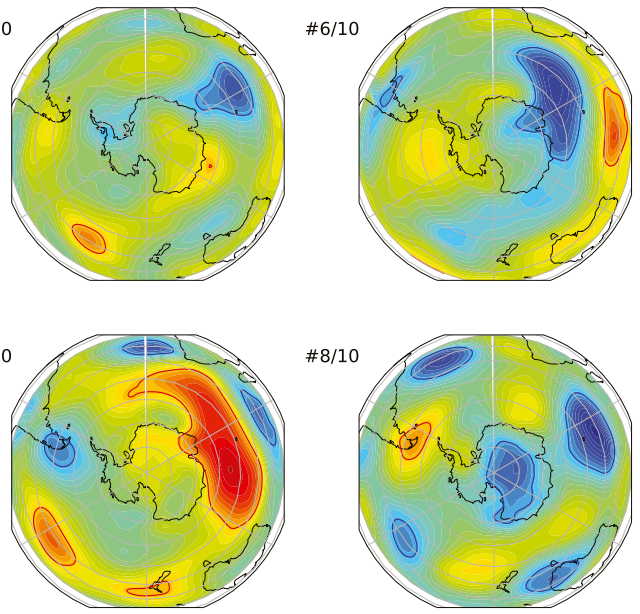

\#8/10

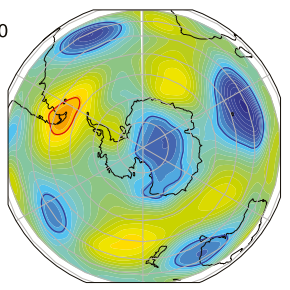

\#9/10

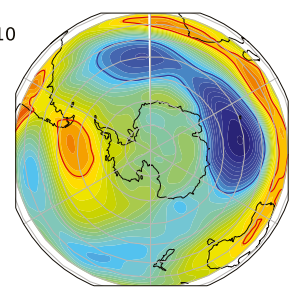

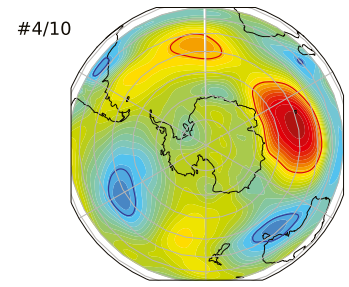

0.50

75

0.25

0.00

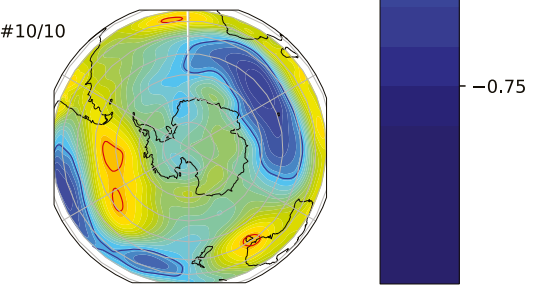

FIG. 9. Teleconnections between the clusters and $Z_{700}$ in the Southern Hemisphere. (left) Linear correlations between the austral summer (NDJF) seasonal number of occurrences of each cluster and the seasonal mean $Z_{700}$ fields for the period from $1979 / 80$ to $2017 / 18$. Solid red and blue lines show positive and negative correlations, respectively, that are significant at the $95 \%$ confidence level according to a Bravais-Pearson test, with a 5\% false discovery rate considered for field significance assessment. (right) As in the left panels, but with partial linear correlations, after removal of the seasonal mean SAM index defined by Marshall (2003).

(e.g., positive correlations for regimes 2, 3, 4, 7 and negative ones for $6,8,9$, and 10 , all of them being mostly independent from the SAM). Some of these signals correspond to wavenumber 4 wave patterns (e.g., for regimes 2 and 8), that modulate the zonally symmetric geopotential height associated with the canonical SAM signature in the midlatitudes (e.g., Cash et al. 2002; Pohl and Fauchereau 2012). Regimes 3, 7, and 9 are also associated with atmospheric configurations reminiscent of the first component of the Pacific-South American mode (e.g., Mo and Higgins 1998; Mo and Paegle 2001). Regional-scale signals in the midlatitudes near Kerguelen could be direct consequences of the short-lived geopotential anomalies recorded during the regimes (Fig. 6), that could modify seasonal mean fields through upscaling (i.e., agglomerative) effects. In online the supplemental material (supplemental Figs. 12-14), we explore this issue and show hemispheric-scale $Z_{700}$ anomalies during regime daily occurrences. Largest amplitudes are logically circumscribed to the Kerguelen sector, 

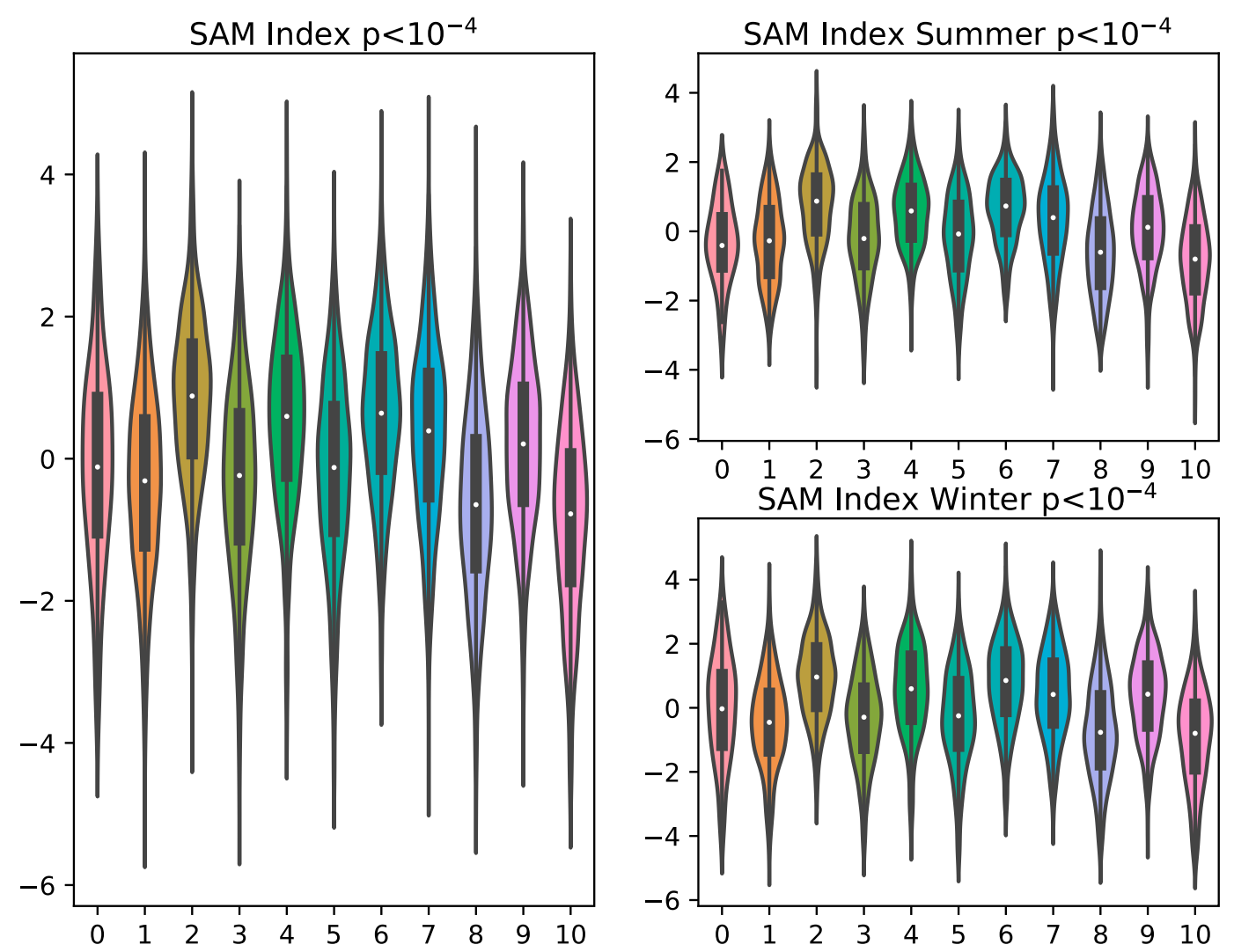

FIG. 10. Violin plot of the daily SAM index during regime occurrences for (left) the whole period and the austral (top right) summer (NDJF) and (bottom right) winter (JJAS) seasons. The violin plots show the whole statistical distribution. The boxes extend from the first to the third quartile, and the white dot represents the median value. The whiskers extend to the extreme values. The "zero" category corresponds to the days with largest regime uncertainties, with less than 8 ERA5 members of 10 ascribed to the same regime. The significance ( $p$ value) of an analysis of variance as estimated by a Fisher test is labeled over each panel.

where regimes are defined. Part of the zonally asymmetric features noted in Fig. 9 match the short-lived anomalies occurring during regime occurrences. Another salient result is that short-lived geopotential height anomalies associated with the regimes over Antarctica are significant but of weak amplitude. Their sign and spatial signature are coherent with the teleconnections of Fig. 9. This indicates that weak daily anomalies have cumulative effects when integrated over a whole season (either summer or winter), and explain the strong relationships discussed above between the Kerguelen regimes and seasonal SAM variability.

Figures 10 and 11 allow for a more detailed analysis of the relationships between the regimes and the SAM at the seasonal and daily time scales. During regime occurrences, the daily SAM index shows very large intraregime spread, describing variable SAM conditions within each regime. Yet, some regimes are clearly associated with strong shift in the corresponding daily SAM index, either toward its positive (for regimes 2, 4, 6, and 7) or negative (1,8, and 10) phases. These regimes correspond to those associated with significant, spatially coherent, daily $Z_{700}$ anomalies over Antarctica (Figs. 12-14 in the online supplemental material). The correspondence is less clear when considering the seasonal time scale (Figs. 9 and 11), illustrating that the background climate conditions favorable to some regimes do not systematically match the instantaneous configurations recorded during their occurrences (e.g., Fig. 9 vs supplemental Fig. 13). Hence, the regimes associated with the largest phase shifts in the daily SAM index (Fig. 10) are not always those displaying the largest associations with the seasonal mean index (Fig. 11). Although there is an overall good agreement between seasonal and daily time scales, regimes 7 (for both summer and winter seasons) and 10 (with out-of-phase relationships between summer and winter at seasonal scale, but in phase at daily scale) are noticeable exceptions.

Overall, teleconnections with SST fields are generally weaker, more season dependent and less robust than their counterparts with the Southern Hemispheric $Z_{700}$ (Figs. 8 and 9; Figs. 10-12 in the online supplemental material). This clearly suggests that the regimes are more driven by the state of the atmosphere (including, but not limited to, the phase of the SAM) than oceanic or coupled modes of climate variability. The two time scales (daily and seasonal) at which significant relationships are found with the SAM (Figs. 10 and 11; supplemental Figs. 12-14) are clearly indicative of scale interactions in the climate system, seamless SAM variability being 


\begin{tabular}{|c|c|c|c|c|}
\hline & \multicolumn{2}{|c|}{ Austral Summer } & \multicolumn{2}{c|}{ Austral Winter } \\
\cline { 2 - 5 } & SAM & ENSO & SAM & ENSO \\
\hline \#1 & -0.19 & -0.02 & -0.32 & -0.24 \\
\hline \#2 & $\mathbf{0 . 6 3}$ & -0.27 & $\mathbf{0 . 6 0}$ & 0.25 \\
\hline \#3 & -0.16 & -0.13 & -0.37 & -0.03 \\
\hline \#4 & 0.28 & -0.16 & $\mathbf{0 . 4 2}$ & 0.30 \\
\hline \#5 & -0.25 & 0.11 & -0.39 & -0.02 \\
\hline \#6 & $\mathbf{0 . 5 6}$ & -0.08 & $\mathbf{0 . 5 7}$ & 0.11 \\
\hline \#7 & 0.11 & 0.01 & -0.17 & 0.23 \\
\hline \#8 & 0.04 & 0.04 & -0.53 & -0.48 \\
\hline \#9 & 0.19 & 0.19 & $\mathbf{0 . 3 8}$ & 0.12 \\
\hline \#10 & $\mathbf{0 . 3 2}$ & $\mathbf{0 . 3 2}$ & -0.59 & -0.26 \\
\hline
\end{tabular}

FIG. 11. Interannual correlations between seasonal regime occurrence and the seasonal mean SAM and ENSO indices for the period from NDJF 1979/80 to 2017/18 (for summer) and from JJAS 1979 to 2018 (for winter). Significant positive and negative correlations at the $95 \%$ confidence level according to a Bravais-Pearson test are in red and blue, respectively.

associated with differentiated regime seasonal occupations, that mostly consist in a variable number of short-lived sequences (supplemental Figs. 2 and 3).

\section{c. Local-scale atmospheric anomalies on the Kerguelen Islands}

In this section, we assess the local-scale effects of the regimes on the Kerguelen Archipelago. To that end, we make use of the observational time series. The longest and most reliable observations are in the main settlement of Port-aux-Français (see Fig. 1 for location and section 2a for details). There, both atmospheric measurements (of the common meteorological variables) and SWT are performed over at least a few decades, at daily or subdaily timesteps, and with a very small number of missing values. This allows for the calculation of climate anomalies against a reference climatology averaged over the observational periods. Yet, the particular situation of the scientific station (east of Kerguelen, sheltered in the "Morbihan Bay") raises the questions of its spatial representativeness, as well as the spatial contrasts it could show with other sites on Kerguelen. These issues are addressed using additional observations collected at various in situ atmospheric and oceanic stations (Figs. 1 and 2), for which the availability period is too short to estimate robust climate anomalies against a reference mean climatology. Thus, in this work, we only consider climate anomalies at Port-aux-Français and spatial contrasts between all stations and Port-aux-Français (i.e., daily differences between all available variables at all locations and those recorded at the scientific base) and assess to what extent both anomalies and spatial differences are modulated by the weather regimes.

Figure 12 shows the composite anomalies of atmospheric variables measured at the synoptic station of Port-aux-Français.
The mean climatologies and monthly variability of all variables are shown in Fig. 15 in the online supplemental material, and seasonal anomalies during regime occurrences (remarkably similar in summer and in winter, except for surface radiation) are displayed by Figs. 16 and 17 in the online supplemental material. Local-scale SLP anomalies recorded at Port-auxFrançais are very consistent with the regional-scale geopotential height changes associated with the regimes (Fig. 6). There is also a good agreement between observed temperature measured locally and regional-scale temperature composite anomalies produced by ERA5. Regimes tend to produce quite similar anomalies in Tn and Tx, which is consistent with our hypothesis giving to atmospheric dynamics a predominant role to drive temperature variability around Kerguelen. This point is further supported by the relative weak differences in global surface radiation from one regime to another, suggesting that changes in the radiative budget are not the primary cause for temperature variability. However, more detailed analysis of temperature reveals that the "warm" regimes are also those showing the largest DTR values. The "warm/high-DTR" regimes at Port-aux-Français also tend to be associated with rather low relative humidity (Fig. 12; even if positive specific humidity anomalies prevail for regime 4; Fig. 7), positive SLP (i.e., high pressure) anomalies, and, to a lesser extent, anomalously weak wind speed. High-DTR days tend to coincide with atmospheric blockings or anticyclonic conditions. Bivariate analysis of DTR and wind confirms that low wind speeds are a necessary (but not sufficient) condition for large DTR (not shown), probably due to a stronger influence of land heating in the afternoon, hereby promoting an increase in Tx and a larger difference with preceding Tn. Another hypothesis involves an overestimation of Tx due to poorly ventilated solar radiation shields (Georges and Kaser 2002). Daily precipitation anomalies mostly differ from one regime to another because of changes in their wet intense and extreme values (above the 75 th percentile). Median values are less variable from one regime to another, and dry extremes are constant in all regimes, because dry days are present in all regimes. Hence, this is mostly the intraregime spread of the distribution that differs across regimes.

Figure 13 assesses to which extent interannual climate variability at Port-aux-Français is driven by the weather regimes. Most regimes associated with significant short-term anomalies at the daily time scale (Fig. 12) have significant influence at the seasonal scale and drive part of interannual variability (Fig. 13). This is for instance the case for regimes 2 and 4 favoring warm conditions (especially in $\mathrm{Tx}$, leading thus to strong DTR) under high SLP conditions. Regimes 8, 9, and 10 show opposite results, while 3,6 , and 7 are neutral. As for short-term anomalies, relationships with precipitation amounts are weak and uncertain. Despite their weak temporal persistence, the regimes are also relevant to monitor part of lowerfrequency variability ranges.

Spatial contrasts of daily temperature and precipitation during regime occurrences are next addressed (Fig. 14). Spatial differences between the sites show some seasonal dependency, especially for Tx (Fig. 18 in the online supplemental material), with quite uniform air temperature in winter but differences 

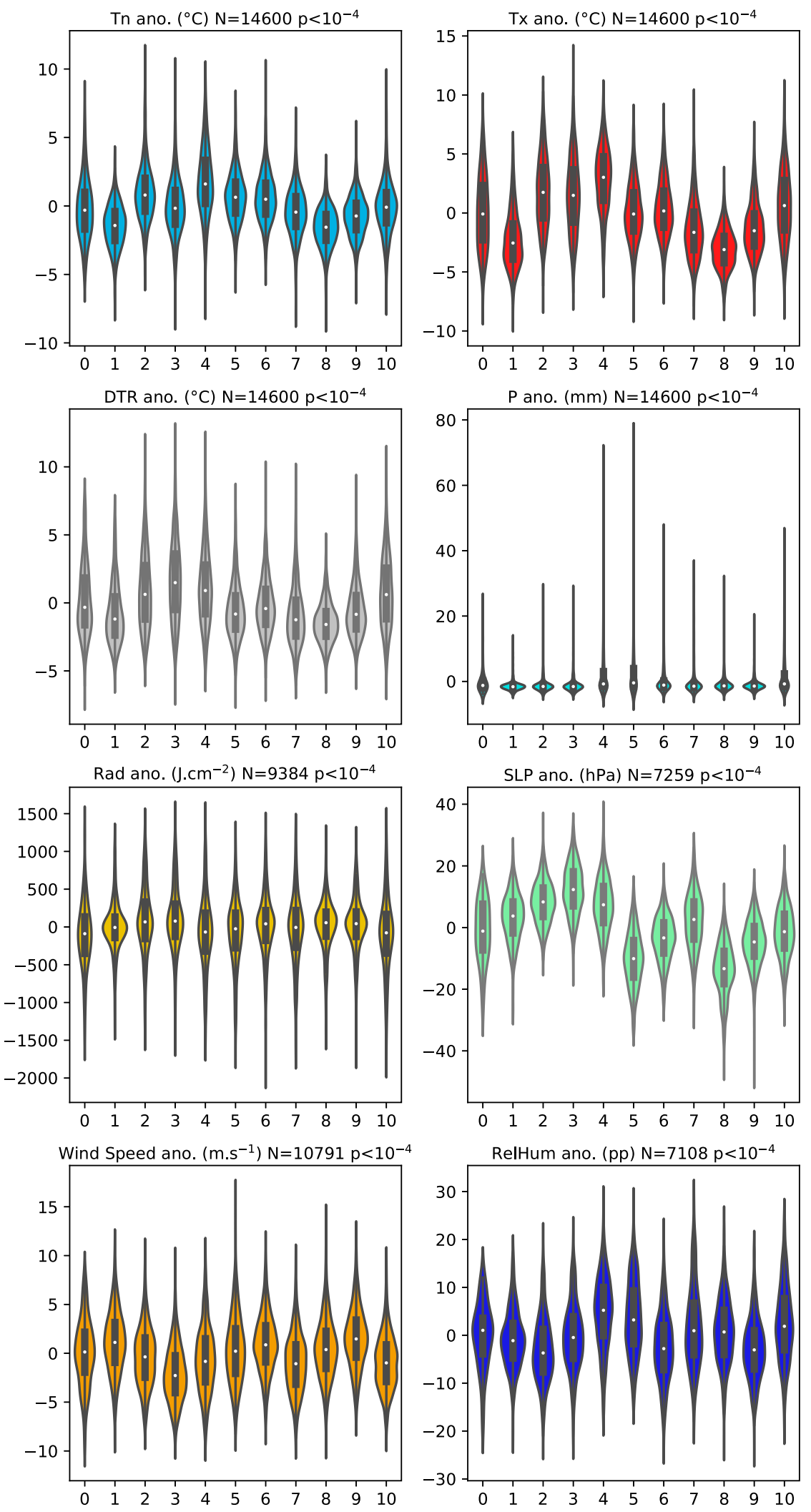

FIG. 12. Composite anomalies of meteorological variables measured at the weather station of Port-aux-Français during the regime occurrences with respect to their respective 40-yr 


\begin{tabular}{|c|c|c|c|c|c|c|c|c|}
\hline & P & Tn & Tx & DTR & SLP & $\mathbf{W}_{\text {speed }}$ & RH & Rad \\
\hline \multirow{2}{*}{ \#1 } & -0.11 & -0.16 & -0.01 & 0.17 & 0.26 & -0.17 & -0.12 & 0.09 \\
& -0.09 & -0.33 & -0.41 & -0.35 & -0.12 & 0.28 & 0.52 & 0.07 \\
\hline \multirow{2}{*}{ \#2 } & -0.12 & $\mathbf{0 . 3 7}$ & $\mathbf{0 . 6 1}$ & $\mathbf{0 . 6 3}$ & $\mathbf{0 . 3 7}$ & -0.00 & -0.34 & 0.63 \\
& -0.16 & $\mathbf{0 . 3 7}$ & $\mathbf{0 . 6 1}$ & $\mathbf{0 . 6 7}$ & $\mathbf{0 . 6 1}$ & -0.06 & -0.35 & -0.07 \\
\hline \multirow{2}{*}{ \#3 } & $\mathbf{0 . 1 9}$ & 0.08 & 0.02 & -0.06 & 0.07 & -0.52 & 0.35 & -0.16 \\
& -0.06 & 0.18 & 0.06 & -0.12 & $\mathbf{0 . 3 5}$ & -0.16 & -0.01 & -0.11 \\
\hline \multirow{2}{*}{ \#4 } & -0.02 & $\mathbf{0 . 5 0}$ & $\mathbf{0 . 5 2}$ & $\mathbf{0 . 3 1}$ & 0.27 & -0.27 & -0.10 & 0.12 \\
& 0.03 & $\mathbf{0 . 6 5}$ & $\mathbf{0 . 7 0}$ & $\mathbf{0 . 4 7}$ & $\mathbf{0 . 7 3}$ & -0.33 & -0.55 & -0.35 \\
\hline \multirow{2}{*}{ \#5 } & 0.26 & -0.11 & -0.28 & -0.36 & -0.30 & 0.22 & 0.49 & -0.39 \\
& 0.06 & -0.20 & -0.23 & -0.18 & -0.49 & -0.18 & 0.23 & 0.11 \\
\hline \multirow{2}{*}{ \#6 } & -0.09 & 0.11 & 0.18 & 0.19 & 0.11 & 0.21 & -0.43 & 0.54 \\
& 0.07 & 0.23 & 0.27 & 0.21 & 0.06 & $\mathbf{0 . 3 4}$ & -0.33 & -0.11 \\
\hline \multirow{2}{*}{ \#7 } & 0.02 & 0.16 & 0.13 & 0.04 & 0.18 & -0.56 & 0.66 & -0.24 \\
& 0.07 & 0.25 & 0.17 & -0.01 & -0.04 & -0.35 & -0.39 & -0.06 \\
\hline \multirow{2}{*}{ \#8 } & 0.15 & -0.36 & -0.49 & -0.42 & -0.18 & 0.26 & -0.06 & -0.19 \\
& -0.02 & -0.69 & -0.72 & -0.47 & -0.64 & 0.18 & 0.57 & 0.35 \\
\hline \multirow{2}{*}{ \#9 } & -0.20 & -0.40 & -0.45 & -0.30 & -0.39 & 0.36 & -0.30 & -0.20 \\
& 0.02 & -0.16 & -0.16 & -0.08 & -0.05 & 0.15 & 0.44 & 0.07 \\
\hline \multirow{2}{*}{ \#10 } & 0.05 & -0.23 & -0.36 & -0.36 & -0.33 & 0.35 & 0.11 & -0.39 \\
& 0.09 & -0.47 & -0.65 & -0.61 & -0.72 & -0.04 & 0.24 & 0.25 \\
\hline
\end{tabular}

FIG. 13. Interannual variability of weather regimes and climate variability recorded at the synoptic weather station of Port-auxFrançais. Linear correlations between the number of regime occurrences during each austral summer season of the period and seasonal mean atmospheric variables observed on the Kerguelen Islands (precipitation, daily minimum and maximum temperature, diurnal thermal range, sea level pressure, wind speed, relative humidity, and global surface radiation). In each cell, the top number is for the austral summer season (NDJF from 1979/80 to 2017/18) and the bottom number is for the austral winter season (JJAS from 1979 to 2018). Red and blue numbers indicate positive and negative correlations, respectively, that are significant at the $95 \%$ confidence level according to a Bravais-Pearson test.

reaching up to $10^{\circ} \mathrm{C}\left(5^{\circ} \mathrm{C}\right.$ on average $)$ in summer, for example, between Port-aux-Français and Cap Cotter or Port Christmas. This is due to the sheltered location of Port-aux-Français (Fig. 1), placing it under a larger influence from the land heating during summer afternoons. However, even in summer, spatial contrasts remain generally of smaller amplitude than the composite anomalies recorded at Port-aux-Français (Fig. 12). Regime influence is strongest for Tx at Cap Cotter and Port Christmas. For these stations, both located on the northern shore of the archipelago, northeasterly anomalies (or easterly anomalies for Port Christmas) occurring during regimes 3 and 4 enhance oceanic influence and favor cool conditions. The local configuration of the coastlines seems decisive to modulate local temperature changes during summer afternoons, with opposite effects of land and sea winds. On average, Cap Cotter is $4^{\circ} \mathrm{C}$ colder than Port-aux-Français during regimes 2,3 , and 4 , against only $1^{\circ} \mathrm{C}$ for regimes $1-8$. This is due to a stronger land influence at Port-aux-Français, allowing for larger afternoon warming, especially in summer (Figs. 18 and 19 in the online supplemental material). In this regard, the site of Port-auxFrançais, where the Météo-France synoptic weather station is operated since the 1950s, appears as weakly representative of most other sites of the archipelago, due to its sheltered situation enhancing temperature variability and seasonality under stronger land surface influence.

Precipitation differences from one site to another need to be considered with caution, because of the skewed distribution of this variable (as confirmed by the differences between the median and the mean in Fig. 11). Extreme values of spatial contrasts often exceed $15 \mathrm{~mm}$ at Armor and Sourcils Noirs, reach $25 \mathrm{~mm}$ at Cap Cotter, reach $50 \mathrm{~mm}$ at Port Christmas, and even exceed $100 \mathrm{~mm}$ at Mortadelle, the two latter stations being also the westernmost and the wettest of all sites. These values illustrate that heavy rainfall can occur at a given station while weak rainfall or even dry conditions prevail elsewhere. Intense or extreme precipitation events can have limited spatial extension or strong spatial variability, a result that is particularly meaningful at Kerguelen where convective precipitations are virtually null. For most stations, median values for all regimes remain weak, because most days are either dry, or associated with low precipitation amounts (Fig. 12; Fig. 15 in the online supplemental material). Port Christmas shows the largest differences with Port-aux-Français: this is also the most distant station. The wettest conditions there result from moisture advections from the northeast, perpendicular to the coast and facing the main relief. The predominant role of advections combined to orographic forcing is confirmed at Armor, with northerly, northeasterly, and easterly anomalies during regimes 5,7 , and 8 favoring orographic ascents. This is even clearer at Sourcils Noirs, where dry conditions prevail locally during regimes associated with northerly anomalies (regimes 4 and 5), while wet conditions are recorded under southerly or southeasterly anomalies (regimes 7, 8, and 9) facing the local reliefs. Finally, regimes favoring northerly anomalies, and advections of moisture from lower latitudes, generally favor wet conditions on Kerguelen, east of its main reliefs: this statement is verified both at Port-aux-Français and Mortadelle, even though the spatial contrasts between both sites is complex and regime dependent. Site topography and day-to-day variability internal to the regimes, both driving the areas under the largest topographic ascents, are hypothesized to control the spatial distribution of precipitation amounts.

\section{d. Nearshore oceanic anomalies}

Figures 15 and 16 extend these analyses to nearshore SWT variability. Figure 15 presents composite anomalies for SWT

mean climatology for the period 1979-2018. Variables considered are daily maximum (Tx) and minimum $(\mathrm{Tn})$ air temperature at $2 \mathrm{~m}\left({ }^{\circ} \mathrm{C}\right)$, diurnal thermal range anomalies $\left({ }^{\circ} \mathrm{C}\right)$, precipitation anomalies $(\mathrm{mm})$, global surface radiation $\left(\mathrm{J} \mathrm{cm}^{-2}\right)$, sea level pressure $(\mathrm{hPa})$, wind speed $\left(\mathrm{m} \mathrm{s}^{-1}\right)$, and relative humidity (percentage points). The number $N$ of data included in each analysis is labeled in each panel title. Violin-plot representation, sample construction, and statistical significance are as in Fig. 10. 

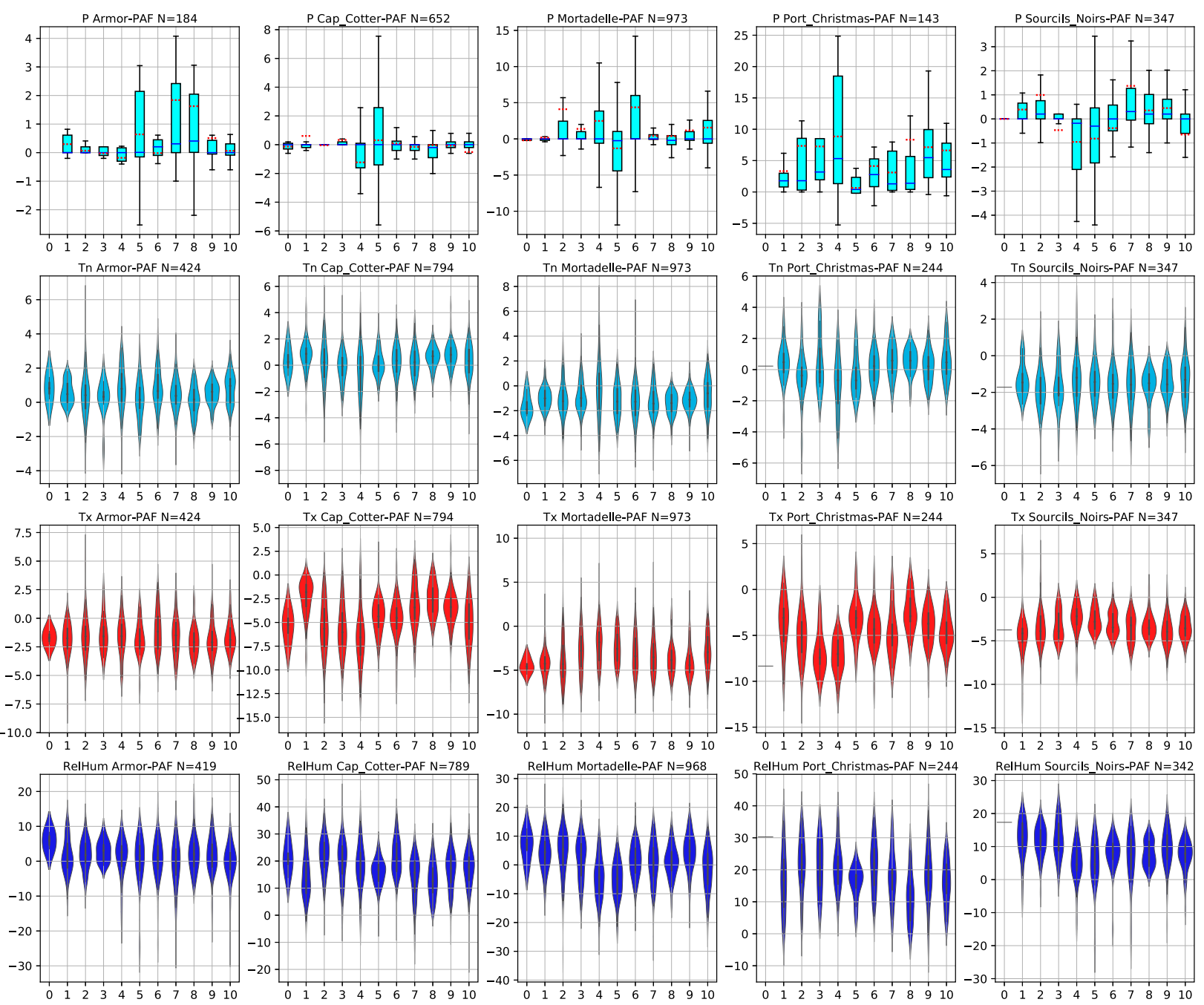

FIG. 14. Daily differences in (top) precipitation (mm), (top middle) $\mathrm{Tn}\left({ }^{\circ} \mathrm{C}\right)$, (bottom middle) $\mathrm{Tx}\left({ }^{\circ} \mathrm{C}\right)$, and (bottom) relative humidity (percentage points) between Kerguelen weather stations (Armor, Cap Cotter, Mortadelle, Port Christmas, and Sourcils Noirs) and the Port-aux-Français reference time series for the period NDJF 2012-18. The number $N$ of daily data included in each analysis is labeled in each panel title. Boxplot representation are as in Fig. 5, with outliers omitted for readability. Violin-plot representation, sample construction, and statistical significance are as in Fig. 10.

measurements at Port-aux-Français. Corresponding climatology is shown in Fig. 20 in the online supplemental material. SWT anomalies are very consistent with air temperature anomalies (Fig. 12), with, for example, regimes 2 and 4 (1 and 8) corresponding to the largest positive (negative) departures from the mean climatology. Although strong intraregime variability is found, regime occurrences strongly and significantly discriminate SWT variability, denoting the predominant atmospheric forcing on near-surface water temperature. The influence of the regimes shows some seasonal dependency, with less coherence between air and water temperature in winter. Some regimes (e.g., 1, 3, or 7) are also associated with anomalies that strongly differ from one season to another. Easterly and southeasterly wind anomalies occurring during regimes 1 and 7 could favor the transport of seawater toward the Morbihan Bay, which leads to cool SWT therein. In winter, meridional anomalies seem to have a larger influence on SWT anomalies, probably due to the proximity of the polar front and subantarctic water close to the Kerguelen-Heard Plateau.

Figure 16 presents the daily differences in SWT between Port-aux-Français and remote sites, for the austral summer season. Figure 22 in the online supplemental material shows results for the winter season: the very different annual cycles of SWT from one site to another, mostly caused by the strong summer warming at Port-aux-Français (supplemental Fig. 21), make annual analyses irrelevant. PAF_5m shows SWT measurements at $5 \mathrm{~m}$ below the surface, as compared with the tide gauge reference time series: differences are small (and even weaker in winter, supplemental Fig. 22) and mostly document SWT stratification in the Morbihan Bay. Other loggers located in that bay (Channer, Haute, Longue, and Suhm) tend to show a similar behavior, despite a weaker SWT variability. The 

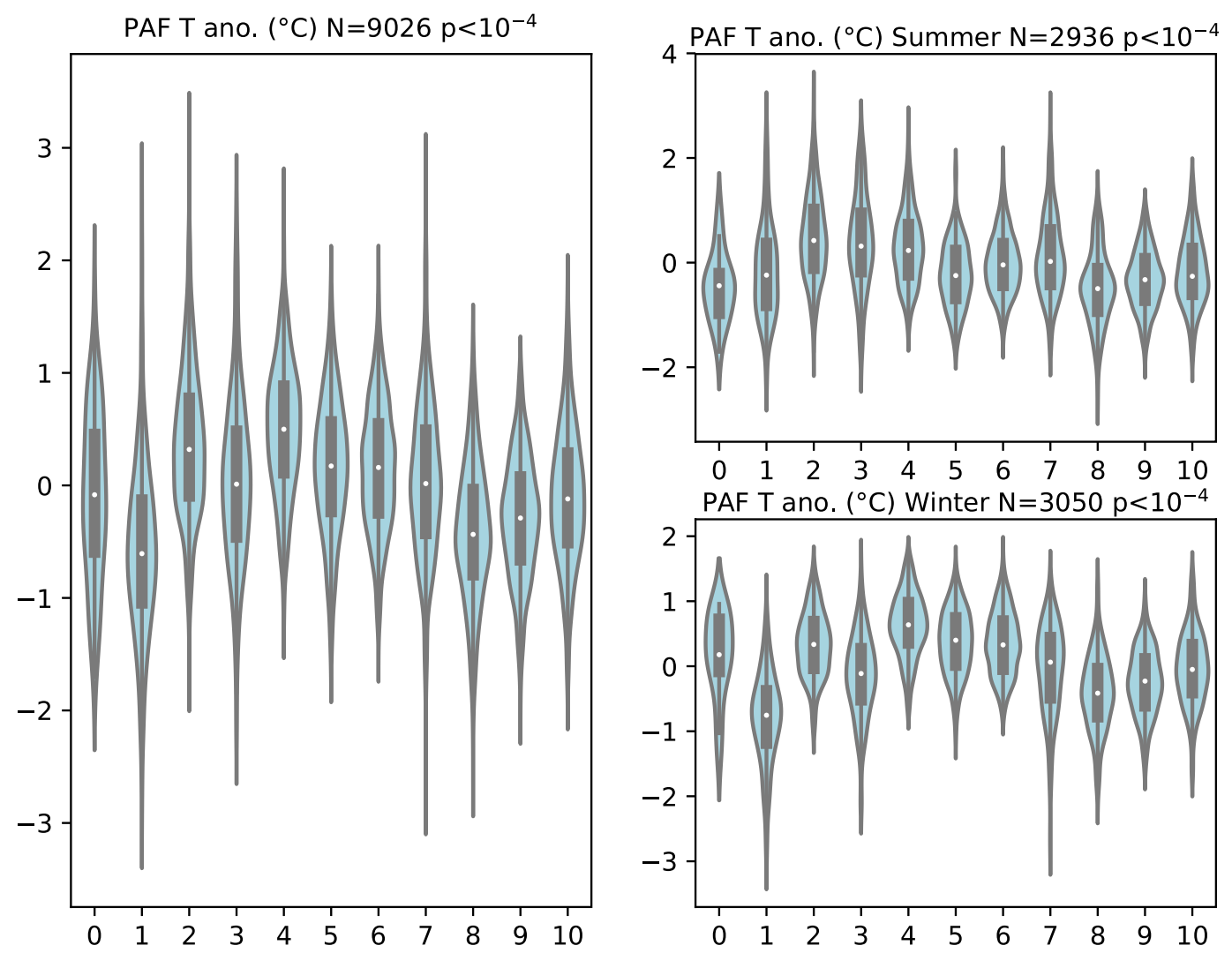

FIG. 15. As in Fig. 12, but for water temperature anomalies $\left({ }^{\circ} \mathrm{C}\right)$ measured at the tide gauge in Port-aux-Français for the period from 5 Apr 1993 to 31 Dec 2018, with a 1-yr gap in 2015, for (left) the whole period andthe; austral (top right) summer (NDJF) and (bottom right) winter (JJAS) seasons.

warmer (colder) regimes at Port-aux-Français (Fig. 15) are those showing negative (positive) differences with other sites (Fig. 16), indicative of larger SWT variance in Port-aux-Français caused by its sheltered situation. The dataloggers of Portes Noires, Port Couvreux and even more clearly Monaco (Figs. 1 and 2) are under strong oceanic influence, as shown by their weak annual cycles maximizing seasonal contrasts with Port-aux-Français (supplemental Fig. 21). SWT conditions in Monaco appear generally quite stable, and differences with Port-aux-Français are therefore mainly due to local SWT changes there. Portes Noires is close to Monaco, but in a fjord and thus in a much more sheltered site, causing stronger local effects (as seen by the wider range of SWT in summer: Fig. 16). Along the northern coast in summer, Port Couvreux and Port Christmas tend to warm up under northerly anomalies (regimes 4 and 5, and 7 to a lesser extent), advecting warmer water and air masses from the lower latitudes (Fig. 6). The singular behavior of regime 8 is mostly explained by the strong cooling at Port-aux-Français. The situation is radically different in winter (supplemental Fig. 22), with relatively warmer conditions during regimes 8 and 9 characterized by southerly anomalies (Fig. 6) that keep these sites protected from cold advections from the higher latitudes.

Taken together, the results of sections $3 \mathrm{c}$ and $3 \mathrm{~d}$ confirm (i) the major influence of land-sea contrasts to drive air temperature variability at local scales, (ii) the strong influence of topographic forcing to modulate rainfall amounts and their spatial distribution, (iii) the strong association between air temperature and nearshore SWT. They also suggest that weather regimes conceal strong internal variability, responsible for large residual spread in local weather conditions.

\section{Conclusions and perspectives}

This study defines weather regimes around the Kerguelen region, with the objectives to better understand the scale interactions between climate and weather, on the one hand, and between hemispheric-scale, regional-scale, and local-scale dynamics and variability, on the other hand. The synoptic regimes help assess the mechanisms controlling air and water temperature variability near Kerguelen, underlining the predominant role of meridional advections favored by the transient perturbations developing in the midlatitudes. Even though solar radiation has a weaker influence on air temperature, blocking days with clear-sky and, more importantly, low winds, are found to favor afternoon warming, thereby leading to larger DTR. The regimes show less skill for explaining precipitation variability, either at daily or seasonal time scales. Analysis of the relationships between synoptic regimes and large-scale climate drivers highlight the primary role of the SAM, that 

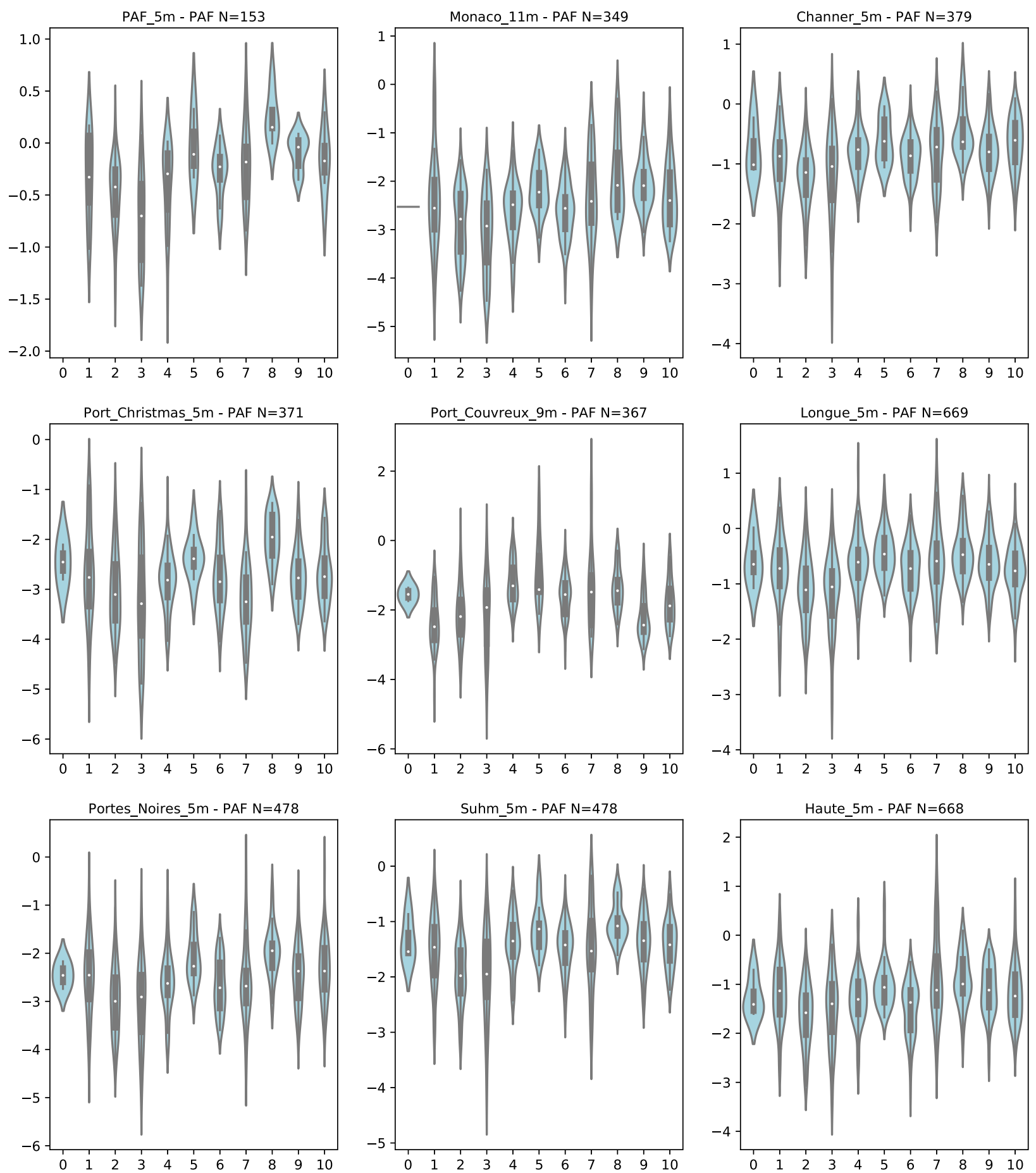

FIG. 16. As in Fig. 14, but for daily differences in water temperature $\left({ }^{\circ} \mathrm{C}\right)$ between Kerguelen ocean dataloggers and Port-aux-Français reference tide gauge time series in the austral summer season (NDJF), based on daily measurements performed over the period from 6 Jan 2012 to 31 Dec 2018.

significantly modulates regime seasonal frequencies throughout the year. The remote influence of the SAM is not only verified at the seasonal time scale, but also at the daily scale of weather regime occurrences: significant anomalies of geopotential height, highly coherent spatially, prevail over
Antarctica during short-lived regime sequences. Even if these anomalies are statistically significant, they remain yet of much smaller magnitude than regional-scale geopotential perturbations associated with the regimes: the teleconnection with seasonal SAM variability is mostly through the cumulative 
effect of sequences of a few days, each showing weak but large-scale signals over the southern high latitudes. Although significant associations are also found with tropical SSTs, relationships are both weaker and more season dependent. This result differs from regions at lower latitudes (e.g., southern Africa or New Zealand; e.g., Manatsa et al. 2013; Jiang et al. 2013), placed under the combined influence of tropical and polar climate variability.

This work makes use of observational measurements performed on the field in the Kerguelen Islands. Long-term, reliable atmospheric and shallow oceanic measurements have been performed for decades at the Port-aux-Français station, which is yet located in a sheltered bay in the eastern part of the main island, leeward of the main reliefs. Observed air temperature and humidity, atmospheric pressure, and surface radiation during regime occurrences show good agreement with reanalyzed variables. SWT and air temperature show high covariability and a consistent response to regime transient perturbations. Yet, these variables are not representative of the conditions that prevail elsewhere on the islands. Analysis of spatial differences with remote observation sites reveal lower annual temperature ranges in the sites situated under a larger oceanic influence. Advective processes are once again a key mechanism that largely controls the local climate, and its spatial variability caused by exposure contrasts. This is especially true when comparing SWT or precipitation measurements along the northern and southern shores of the islands. By modulating wind speed and direction, mostly through geostrophy, the regimes also modify the mixing of the air and water masses, and lead to modifications in the vertical profiles of temperatures. This result, which remains to be assessed in detail, has nonetheless been verified by comparing SWT measurements at $5 \mathrm{~m}$ and below the surface at Port-aux-Français on the one hand, and Port-aux-Français and Mortadelle (159 m MSL) on the other hand. Such spatial contrasts of SWT, precipitation and air temperature, even if they are not easy to interpret because of the numerous mechanisms at play, all show nonnegligible values that require more in-depth analyses at short time scales. They also illustrate that the reference time series recorded for decades at Port-aux-Français are not representative of the various climate conditions that prevail elsewhere in Kerguelen, with local particularities that modify both variability and seasonality in daily precipitation and air temperature. There is therefore a strong need to maintain these observational networks, to monitor climate variability and environmental changes, and account for their spatial differentiations across the archipelago.

As a result of a combination of orographic and dynamic forcings, scale interactions linking weather to climate are a key and highly relevant issue to explore at and around Kerguelen. Such studies encompassing both transient interannual and (multi-) decadal scales are nonexistent in the region, despite the major low-frequency variability that occurred in the $\mathrm{SH}$ since the early twentieth century and led to deep environmental changes and perturbations. Of particular importance is the latitudinal shift of the storm tracks, and the contrasted effects it could have caused on the northern and southern sides of the Kerguelen reliefs. Yet, none of the regimes shows significant long-term change in its frequency. A first hypothesis to explain such stationarity is that the regimes were defined on a period too short and too recent to accurately depict the low-frequency changes recorded in the $\mathrm{SH}$ over the twentieth century (in agreement with Favier et al. 2016). Applying the same clustering approach on long-term reanalyses [e.g., the twentieth-century reanalyses (Slivinski et al. 2019) or ECMWF twentieth-century reanalysis (ERA-20C; Poli et al. 2016)] and climate projections (e.g., CMIP6 simulations of past and future climate change; Eyring et al. 2016) is among our first priorities for future work. Yet, a second hypothesis may be at the origin of the regime stability: the low-frequency changes could occur inside the regimes and, thus, be poorly depicted by frequency changes in regime occupations. This would be consistent with the results of Pohl and Fauchereau (2012) at the scale of the whole SH or Parsons et al. (2014) at the regional scale of New Zealand. A tracking for synoptic centers of action may prove a relevant and complementary tool to address such issues and assess the long-term changes on synoptic systems and configurations associated with ongoing climate change.

Acknowledgments. The authors thank the Journal of Applied Meteorology and Climatology editorial staff and two anonymous reviewers whose constructive comments helped to improve this paper. This work is a contribution to program 1044-Proteker of the French Polar Institute and to the French LTSER Zone Atelier Antarctique (ZATA, CNRS INEE). The distributed weather station network at Kerguelen was funded by IPEV-1048 GLACIOCLIM-KESAACO and LEFE-INSU KCRUMBLE programs. Logistical supply to the Kerguelen Islands was provided by the French Polar Institute. We are indebted to the National Nature Reserve of the French Southern Territories and crews of RVs Commerson and La Curieuse who provided technical assistance in the field. All analyses were made with Python (numpy, pandas, scipy, sklearn, math, matplotlib, cartopy, seaborn, and netCDF4), the developers of which are thanked. Calculations were performed using HPC resources from DNUM Centre de Calcul de l'Université de Bourgogne (CCUB).

Data availability statement. Hydrographic data at Port-auxFrançais were provided by the French tide gauge network SNO ROSAME (CNRS INSU; http://www.legos.obs-mip.fr/observations/ rosame). Local SWT data at other stations were retrieved from http:// www.proteker.net/-Thermorecorders-html?lang=en. Météo-France collects the meteorological data from Port-aux-Français, which are partly available at https://www.infoclimat.fr/observationsmeteo/temps-reel/iles-kerguelen-port-aux-francais/61998.html. Meteorological data recorded at other sites in Kerguelen are accessible at http://pp.ige-grenoble.fr/pageperso/faviervi/kesaaco/ AWS.php. ERA5 data are provided by ECMWF (https:// www.ecmwf.int/en/forecasts/datasets/reanalysis-datasets/era5). Global ERSST v5 data are available at https://www.ncdc.noaa.gov/ data-access/marineocean-data/extended-reconstructed-sea-surfacetemperature-ersst-v5. The SAM index was retrieved from https:// climatedataguide.ucar.edu/climate-data/marshall-southern-annularmode-sam-index-station-based. The Niño-3.4 index was retrieved from https://climatedataguide.ucar.edu/climate-data/ nino-sst-indices-nino-12-3-34-4-oni-and-tni. 


\section{REFERENCES}

Abram, N. J., R. Mulvaney, F. Vimeux, S. J. Phipps, J. Turner, and M. H. England, 2014: Evolution of the southern annular mode during the past millennium. Nat. Climate Change, 4, 564-569, https://doi.org/10.1038/nclimate2235.

Arblaster, J. M., and G. A. Meehl, 2006: Contributions of external forcings to southern annular mode trends. J. Climate, 19, 28962905, https://doi.org/10.1175/JCLI3774.1.

Befort, D. J., S. Wild, T. Kruschke, U. Ulbrich, and G. C. Leckebusch, 2016: Different long-term trends of extra-tropical cyclones and windstorms in ERA-20C and NOAA-20CR reanalyses. Atmos. Sci. Lett., 17, 586-595, https://doi.org/ 10.1002/asl.694.

Benjamini, Y., and D. Yekutieli, 2001: The control of the false discovery rate in multiple testing under dependency. Ann. Stat., 29, 1165-1188, https://doi.org/10.1214/aos/1013699998.

Bergstrom, D., J. Whinam, and L. Belbin, 2002: A classification of Subantarctic Heard Island vegetation. Arct. Antarct. Alp. Res., 34, 169-177, https://doi.org/10.1080/15230430.2002.12003481.

Berthier, E., R. Le Bris, L. Mabileau, L. Testut, and F. Rémy, 2009: Ice wastage on the Kerguelen Islands $\left(49^{\circ} \mathrm{S}, 69^{\circ} \mathrm{E}\right)$ between 1963 and 2006. J. Geophys. Res., 114, F03005, https://doi.org/ 10.1029/2008JF001192.

Bryndum-Buchholz, A., and Coauthors, 2019: Twenty-first-century climate change impacts on marine animal biomass and ecosystem structure across ocean basins. Global Change Biol., 25, 459-472, https://doi.org/10.1111/gcb.14512.

Byrne, M., M. Gall, K. Wolfe, and A. Agüera, 2016: From pole to pole: The potential for the Arctic seastar Asterias amurensis to invade a warming Southern Ocean. Global Change Biol., 22, 3874-3887, https://doi.org/10.1111/gcb.13304.

Carvalho, L. M. V., C. Jones, and T. Ambrizzi, 2005: Opposite phases of the Antarctic Oscillation and relationships with intraseasonal to interannual activity in the tropics during the austral summer. J. Climate, 18, 702-718, https://doi.org/10.1175/ JCLI-3284.1.

Cash, B. A., P. J. Kushner, and G. K. Vallis, 2002: The structure and composition of the annular modes in an aquaplanet general circulation model. J. Atmos. Sci., 59, 3399-3414, https://doi.org/ 10.1175/1520-0469(2002)059<3399:TSACOT>2.0.CO;2.

Cheng, X., and J. M. Wallace, 1993: Cluster analysis of the Northern Hemisphere wintertime 500-hPa height field: Spatial patterns. J. Atmos. Sci., 50, 2674-2696, https://doi.org/10.1175/ 1520-0469(1993)050<2674:CAOTNH > 2.0.CO;2.

Ciasto, L. M., and D. W. J. Thompson, 2008: Observations of largescale ocean-atmosphere interaction in the Southern Hemisphere. J. Climate, 21, 1244-1259, https://doi.org/10.1175/2007JCLI1809.1.

Copernicus Climate Change Service, 2017: ERA5: Fifth generation of ECMWF atmospheric reanalyses of the global climate. Copernicus Climate Change Service Climate Data Store, accessed January 2020, https://cds.climate.copernicus.eu/ cdsapp\#!/home.

Crétat, J., B. Pohl, C. C. Smith, N. Vigaud, and Y. Richard, 2015: An original way to evaluate daily rainfall variability simulated by a regional climate model: The case of South African austral summer rainfall. Int. J. Climatol., 35, 2485-2502, https:// doi.org/10.1002/joc.4155.

Ding, Q., E. J. Steig, D. S. Battisti, and M. Küttel, 2011: Winter warming in West Antarctica caused by central tropical Pacific warming. Nat. Geosci., 4, 398-403, https://doi.org/10.1038/ngeo1129.

Dussaillant, I., and Coauthors, 2019: Two decades of glacier mass loss along the Andes. Nat. Geosci., 12, 802-808, https://doi.org/ 10.1038/s41561-019-0432-5.
Eyring, V., S. Bony, G. A. Meehl, C. A. Senior, B. Stevens, R. J. Stouffer, and K. E. Taylor, 2016: Overview of the Coupled Model Intercomparison Project Phase 6 (CMIP6) experimental design and organization. Geosci. Model Dev., 9, 1937-1958, https://doi.org/10.5194/gmd-9-1937-2016.

Fauchereau, N., B. Pohl, C. J. C. Reason, M. Rouault, and Y. Richard, 2009: Recurrent daily OLR patterns in the southern Africa/southwest Indian Ocean region, implications for South African rainfall and teleconnections. Climate Dyn., 32, 575-591, https://doi.org/10.1007/s00382-008-0426-2.

Favier, V., and Coauthors, 2016: Atmospheric drying as the main driver of dramatic glacier wastage in the southern Indian Ocean. Sci. Rep., 6, 32396, https://doi.org/10.1038/srep32396.

Féral, J.-P., T. Saucède, E. Poulin, C. Marschal, G. Marty, J.-C. Roca, S. Motreuil, and J.-P. Beurier, 2016: PROTEKER: Implementation of a submarine observatory at the Kerguelen islands (Southern Ocean). Underwater Technol., 34, 3-10, https://doi.org/10.3723/ut.34.003.

Fogt, R. L., and D. H. Bromwich, 2006: Decadal variability of the ENSO teleconnection to the high-latitude South Pacific governed by coupling with the southern annular mode. J. Climate, 19, 979-997, https://doi.org/10.1175/JCLI3671.1.

_ Variability, trends, and climate impacts across the Southern Hemisphere. Wiley Interdiscip. Rev.: Climate Change, 11, e652, https://doi.org/10.1002/wcc.652.

Georges, C., and G. Kaser, 2002: Ventilated and unventilated air temperature measurements for glacier-climate studies on a tropical high mountain site. J. Geophys. Res., 107, 4775, https:// doi.org/10.1029/2002JD002503.

Gillett, N. P., T. D. Kell, and P. D. Jones, 2006: Regional climate impacts of the southern annular mode. Geophys. Res. Lett., 33, L23704, https://doi.org/10.1029/2006GL027721.

Hendon, H. H., D. W. Thompson, and M. C. Wheeler, 2007: Australian rainfall and surface temperature variations associated with the Southern Hemisphere annular mode. J. Climate, 20, 2452-2467, https://doi.org/10.1175/JCLI4134.1.

Hersbach, H., and Coauthors, 2020: The ERA5 global reanalysis. Quart. J. Roy. Meteor. Soc., 146, 1999-2049, https://doi.org/10.1002/qj.3803.

Huang, B., and Coauthors, 2017: Extended Reconstructed Sea Surface Temperature version 5 (ERSSTv5): Upgrades, validations, and intercomparisons. J. Climate, 30, 8179-8205, https://doi.org/10.1175/JCLI-D-16-0836.1.

Jiang, N., G. Griffiths, and A. Lorrey, 2013: Influence of large-scale climate modes on daily synoptic weather types over New Zealand. Int. J. Climatol., 33, 499-519, https://doi.org/10.1002/ joc.3443.

Kidson, J. W., 2000: An analysis of New Zealand synoptic types and their use in defining weather regimes. Int. J. Climatol., 20, 299-316, https://doi.org/10.1002/(SICI)1097-0088(20000315) 20:3<299::AID-JOC474>3.0.CO;2-B.

Kushner, P. J., and G. Lee, 2007: Resolving the regional signature of the annular modes. J. Climate, 20, 2840-2852, https://doi.org/ 10.1175/JCLI4106.1.

Lenton, A., and R. J. Matear, 2007: Role of the southern annular mode (SAM) in Southern Ocean $\mathrm{CO}_{2}$ uptake. Global Biogeochem. Cycles, 21, GB2016, https://doi.org/10.1029/2006GB002714.

L'Heureux, M. L., and W. J. Thompson, 2006: Observed relationships between the El Niño-Southern Oscillation and the extratropical zonal-mean circulation. J. Climate, 19, 276-287, https://doi.org/10.1175/JCLI3617.1.

Lim, E., H. H. Hendon, P. Hope, C. Chung, F. Delage, and M. J. McPhaden, 2019: Continuation of tropical Pacific Ocean 
temperature trend may weaken extreme El Niño and its linkage to the southern annular mode. Sci. Rep., 9, 17044, https://doi.org/10.1038/s41598-019-53371-3.

Mackintosh, A. N., B. M. Anderson, A. M. Lorrey, J. A. Renwick, P. Frei, and S. M. Dean, 2017: Regional cooling caused recent New Zealand glacier advances in a period of global warming. Nat. Commun., 8, 14202, https://doi.org/10.1038/ ncomms 14202 .

Manatsa, D., Y. Morioka, S. K. Behera, T. Yamagata, and C. H. Matarira, 2013: Link between Antarctic ozone depletion and summer warming over southern Africa. Nat. Geosci., 6, 934939, https://doi.org/10.1038/ngeo1968.

Marshall, G. J., 2003: Trends in the southern annular mode from observations and reanalyses. J. Climate, 16, 4134-4143, https:// doi.org/10.1175/1520-0442(2003)016<4134:TITSAM>2.0.CO;2.

McGlone, M., J. Wilmshurst, S. Richardson, C. Turney, and J. Wood, 2019: Temperature, wind, cloud, and the postglacial tree line history of sub-Antarctic Campbell Island. Forests, 10, 998, https://doi.org/10.3390/f10110998.

Michelangeli, P.-A., R. Vautard, and B. Legras, 1995: Weather regimes: Recurrence and quasi stationarity. J. Atmos. Sci., 52, 1237-1256, https://doi.org/10.1175/1520-0469(1995)052<1237: WRRAQS $>2.0 . \mathrm{CO} ; 2$.

Mo, K. C., and R. W. Higgins, 1998: The Pacific-South American modes and tropical convection during the Southern Hemisphere winter. Mon. Wea. Rev., 126, 1581-1596, https://doi.org/10.1175/ 1520-0493(1998)126<1581:TPSAMA $>2.0 . C O ; 2$.

— and their downstream effects. Int. J. Climatol., 21, 1211-1229, https://doi.org/10.1002/joc.685.

Parsons, S., A. J. McDonald, and J. A. Renwick, 2014: The use of synoptic climatology with general circulation model output over New Zealand. Int. J. Climatol., 34, 3426-3439, https:// doi.org/10.1002/joc.3919.

Perlwitz, J., 2011: Atmospheric science: Tug of war on the jet stream. Nat. Climate Change, 1, 29-31, https://doi.org/10.1038/ nclimate1065.

Pohl, B., and N. Fauchereau, 2012: The southern annular mode seen through weather regimes. J. Climate, 25, 3336-3354, https://doi.org/10.1175/JCLI-D-11-00160.1.

$\longrightarrow,-$ C. J. C. Reason, and M. Rouault, 2010: Relationships between the Antarctic Oscillation, the Madden-Julian oscillation, and ENSO, and consequences for rainfall analysis. J. Climate, 23, 238-254, https://doi.org/10.1175/2009JCLI2443.1.

— B. Dieppois, J. Crétat, D. Lawler, and M. Rouault, 2018: From synoptic to interdecadal variability in southern African rainfall: Toward a unified view across time scales. J. Climate, 31, 5845-5872, https://doi.org/10.1175/JCLI-D-17-0405.1.

Poli, P., and Coauthors, 2016: ERA-20C: An atmospheric reanalysis of the twentieth century. J. Climate, 29, 4083-4097, https://doi.org/10.1175/JCLI-D-15-0556.1.

Rayner, N. A., D. E. Parker, E. B. Horton, C. K. Folland, L. V. Alexander, D. P. Rowell, E. C. Kent, and A. Kaplan, 2003: Global analyses of sea surface temperature, sea ice, and night marine air temperature since the late nineteenth century. J. Geophys. Res., 108, 4407, https://doi.org/10.1029/2002JD002670.
Reason, C. J. C., and M. Rouault, 2005: Links between the Antarctic Oscillation and winter rainfall over western South Africa. Geophys. Res. Lett., 32, L07705, https://doi.org/10.1029/ 2005 GL022419.

Renwick, J. A., 2004: Trends in the Southern Hemisphere polar vortex in NCEP and ECMWF reanalyses. Geophys. Res. Lett., 31, L07209, https://doi.org/10.1029/2003GL019302.

Richard, Y., and Coauthors, 2013: Temperature changes in the mid- and high-latitudes of the Southern Hemisphere. Int. J. Climatol., 33, 1948-1963, https://doi.org/10.1002/joc.3563.

Sallée, J. B., K. Speer, and R. Morrow, 2008: Response of the Antarctic Circumpolar Current to atmospheric variability. J. Climate, 21, 3020-3039, https://doi.org/10.1175/2007JCLI1702.1.

Schofield, O., H. W. Ducklow, D. G. Martinson, M. P. Meredith, M. A. Moline, and W. R. Fraser, 2010: How do polar marine ecosystems respond to rapid climate change? Science, $\mathbf{3 2 8}$, 1520-1523, https://doi.org/10.1126/science.1185779.

Sen Gupta, A., and M. H. England, 2007: Coupled oceanatmosphere feedback in the southern annular mode. J. Climate, 20, 3677-3692, https://doi.org/10.1175/JCLI4200.1.

Slivinski, L. C., and Coauthors, 2019: Towards a more reliable historical reanalysis: Improvements for version 3 of the Twentieth Century Reanalysis system. Quart. J. Roy. Meteor. Soc., 145, 2876-2908, https://doi.org/10.1002/qj.3598.

Smith, V. R., and L. Mucina, 2006: Vegetation of subantarctic Marion and Prince Edward Islands. The Prince Edward Islands: Land-Sea Interactions in a Changing Ecosystem, S. L. Chown and P. W. Froneman, Eds., African Sun Media, 698-723.

Son, S.-W., and Coauthors, 2008: The impact of stratospheric ozone recovery on the Southern Hemisphere westerly jet. Science, 320, 1486-1489, https://doi.org/10.1126/science.1155939.

Thompson, D. W., and S. Solomon, 2002: Interpretation of recent Southern Hemisphere climate change. Science, 296, 895-899, https://doi.org/10.1126/science.1069270.

,-- P. J. Kushner, M. H. England, K. M. Grise, and D. J. Karoly, 2011: Signatures of the Antarctic ozone hole in Southern Hemisphere surface climate change. Nat. Geosci., 4, 741-749, https://doi.org/10.1038/ngeo1296.

Turner, J., 2004: The El Niño-Southern Oscillation and Antarctica. Int. J. Climatol., 24, 1-31, https://doi.org/10.1002/joc. 965.

Ullah, H., I. Nagelkerken, S. U. Goldenberg, and D. Fordham, 2018: Climate change could drive marine food web collapse through altered trophic flows and cyanobacterial proliferation. PLOS Biol., 16, e2003446, https://doi.org/10.1371/ journal.pbio.2003446.

Vaughan, D. G., and Coauthors, 2013: Observations: Cryosphere. Climate Change: The Physical Science Basis, T. F. Stocker et al., Eds., Cambridge University Press, 317-382.

Verfaillie, D., and Coauthors, 2015: Recent glacier decline in the Kerguelen Islands $\left(49^{\circ} \mathrm{S}, 69^{\circ} \mathrm{E}\right)$ derived from modeling, field observations and satellite data. J. Geophys. Res. Earth Surf., 120, 637-654, https://doi.org/10.1002/2014JF003329.

, V. Favier, H. Gallée, X. Fettweis, C. Agosta, and V. Jomelli, 2019: Regional modeling of surface mass balance on the Cook Ice Cap, Kerguelen Islands $\left(49^{\circ} \mathrm{S}, 69^{\circ} \mathrm{E}\right)$. Climate Dyn., 53, 5909-5925, https://doi.org/10.1007/s00382-019-04904-z. 